\title{
ANTECEDENTES HISTÓRICOS REFERIDOS A LA CAZA DE LOBOS MARINOS Y SU INTERACCIÓN CON EL MEDIO GEOGRÁFICO Y HUMANO EN EL EXTREMO AUSTRAL AMERICANO: EL CASO DEL LOBERO ESCOCÉS WILLIAM LOW
}

\author{
MARCELO MAYORGA Z
}

\section{RESUMEN}

Hacia fines del siglo XVIII e inicios del siglo XIX, se desarrolló en el área de Patagonia, Tierra del Fuego e islas Falkland una incipiente actividad económica, ligada a la explotación de pinnípedos. Una gran número de loberos británicos y estadounidenses se hicieron presente por los intrincados canales de la geografía patagónica, en cuyo contexto, irían adquiriendo una serie de conocimientos respecto del medio geográfico y humano. Con el propósito de contribuir a conocer mayores antecedentes respecto de la presencia de este grupo de navegantes, se analiza desde la perspectiva metodológica de la microhistoria, la trayectoria del lobero escocés William Low, quien encarna desde un caso límite, el modo de vida y circunstancias de gran parte de los cazadores de lobos marinos. Se han constatado una serie de antecedentes desconocidos respecto de las actividades desarrolladas por el lobero Low, quien luego de tres décadas surcando los mares del sur, se retira a una apacible y modesta vida en la isla de Chiloé. ${ }^{1}$

PALABRAS CLAVE: William Low, loberos, Patagonia, Chiloé, indígenas australes.

\section{HISTORICAL BACKGROUND RELATED TO FUR SEALING AND THEIR INTERACTION WITH THE GEOGRAPHICAL AND HUMAN ENVIRONMENT AT THE SOUTHERNMOST AUSTRAL AMERICAN EXTREME: THE CASE OF SCOTTISH SEALER WILLIAM LOW}

\section{ABSTRACT}

By the late XVIIIth century and early XIXth century, an incipient economic activity linked to the exploitation of pinnipeds was developed in the area of Patagonia, Tierra del Fuego, and Falkland Islands. A large number of British and American sealers were present at the intricate channels of the patagonian geography. In this context, they gradually acquire a range of knowledge about the geographical and human environment. With the objective of contributing to learning more about the background presence

a Académico, Facultad de Educación y Ciencias Sociales, Universidad de Magallanes. marcelo.mayorga@umag.cl

1 CD HACS "Identidad del Fin del Mundo: Patagonia, Tierra del Fuego y Antártica", Ministerio de Educación, Chile.

El presente trabajo forma parte de la tesis doctoral denominada "Interacción fronteriza, loberos y aborígenes en Patagonia y Tierra del Fuego en el marco de la expansión europea noroccidental y estadounidense desde fines del siglo XVIII", para la obtención del grado de Doctor en Estudios Americanos, Instituto de Estudios Avanzados (IDEA), Universidad de Santiago. 
of this group of sailors, the career of the Scottish sealer William Low is analyzed using Microhistory as a methodological perspective for this sealer that embodies a borderline case, the lifestyle and the circumstances of many. A number of unknown records have been observed, verifying the activities of Low the sealer, which after three decades sailing around the South Seas gets into retirement, living a quiet and humble existence at Chiloe Island.

KEY WORDS: William Low, sealers, Patagonia. Chiloé, Southern natives, indigenous.

\section{INTRODUCCIÓN}

Hacia fines del siglo XVIII $e$ inicios del siglo XIX, se produjo en el cono sur de América, específicamente en el área de Patagonia, Tierra del Fuego, islas Falkland e islas subantárticas y posteriormente, en el continente antártico, la consolidación de una actividad económica, ligada a la explotación de mamíferos marinos, basada en el aprovechamiento de las pieles (lobo marino fino o de dos pelos, Arctocephalus australis y lobo marino de un pelo o común, Otaria flavescenses) y la grasa (elefante marino, Mirounga leonina) y que a la postre, pasaría a ser la primera actividad económica desarrollada en territorio magallánico (Martinic, 1987, p. 13).

Esta actividad fue llevada a cabo principalmente por marineros de nacionalidad británica y estadounidense y, en menor medida, por naves de bandera francesa, cuyos principales mercados para la comercialización de sus productos, eran distantes puertos en China (Cantón) y Europa (Londres).

Los antecedentes que explican la expansión de los loberos hacia aguas meridionales, están dados en primer lugar, por el impulso generado por las diversas expediciones científico-navales organizadas por las potencias europeas durante el siglo XVIII, entre las que destacan las de los ingleses George Anson (1740), John Byron (1764), James Cook $\left(1^{\circ}\right.$ viaje de 1768 y $2^{\circ}$ viaje llevado a cabo en 1772) y la del francés Louis Antoine de Bougainville (1766), de cuyas publicaciones se derivaron valiosas observaciones, sobre todo, en lo relacionado a la abundancia de mamíferos marinos en el Pacífico Sur (Kirker, 1970, pp. 1417); en segundo lugar, debido a las consecuencias generadas por la independencia de Estados Unidos en 1776, situación que llevaría a su marina mercante a la búsqueda de nuevos mercados, ante la imposibilidad de acceder a los productos y mercados monopolizados por los ingleses (Pereira, 1971, p. 23); y, paralelamente, por el influjo que significó para el comercio internacional, al promediar el siglo XVIII, la apertura del puerto de Cantón en China (Dulles, 1930, pp. 3-4; Greenberg, 1951, pp. 41-48).

A partir de los antecedentes recogidos en las escasas publicaciones o en relaciones viajes dejadas por algunos loberos (sealers) que basaron total o parcialmente sus actividades en el área específica de Patagonia, Tierra del Fuego e islas Falkland, tales como las del británico James Weddell (1825), la de los norteamericanos Charles Barnard (1836), Edmund Fanning (1838) y Benjamin Morrell (1832), han podido conocerse algunos pormenores de sus actividades e interacciones con el medio geográfico y humano en el contexto de sus incursiones cinegéticas, contribuyendo de modo indirecto, al mejor conocimiento de tan inhóspitas tierras (Martinic, 2006; Stackpole, 1953, p. 181), asî como también, de las costumbres y modos de vida de los aborígenes australes (Mayorga, 2010, p. 15).

Con el propósito de contribuir a conocer mayores antecedentes respecto de la presencia de este grupo de navegantes en territorio patagónico, se analizará desde la perspectiva metodológica de la microhistoria, -en particular, lo atingente a la reducción de la escala de observación, la preocupación del indicio como paradigma científico y la utilización intensiva del material documental (Levi, 2003, p. 122)-, la trayectoria del lobero de origen británico William Low, quien encarna desde un caso límite, según refiere Ginzburg (1999, p. 9), el modo de vida y circunstancias de gran parte de los cazadores de lobos marinos y, en este sentido, los testimonios que de Low se han podido compulsar, tienen características tales, que es posible considerarlos representativos de estos sujetos históricos.

En sí misma, la consideración del caso del lobero William Low, resulta ser doblemente relevante, 
por cuanto, de un lado, se vincula directamente con el contexto global, dada su participación en la actividad de la caza de mamíferos marinos, iniciada por los balleneros desde Europa, a la que posteriormente, se incorporaron marineros yankees, para luego, casi en simultaneidad, dar paso a los cazadores de lobos marinos, expansión que significó la incorporación en los circuitos mercantiles de vastos territorios ultramarinos alejados de los tradicionales centros del comercio mundial. Y de otro lado, se inserta en un contexto regional o local, dado que la figura de este lobero británico se encuentra asociada con los esfuerzos iniciales llevados a cabo por Chile para incorporar a la soberanía nacional el Estrecho de Magallanes y territorios adyacentes (lo que se concretó en el año 1843), dado que originalmente se había pensado que fuera Low quien comandase el célebre periplo llevado a cabo a bordo de la goleta Ancud y, adicionalmente, porque este personaje terminaría por radicarse en la isla de Chiloé, para seguir dedicándose a la misma actividad. Sus experiencias y conocimientos habrían de traspasarse a los habitantes de Chiloé y complementarían el patrimonio de conocimientos geográficos de los chiloenses, sustentado en su propia historia y en la interacción con poblaciones canoeras del sur de la isla (Âlvarez et al. 2015, p. 94), quienes previamente y hasta la primera mitad del siglo XIX, se dedicaban a la caza de lobos marinos (Torrejón, et al. 2013, p. 42), ballenas, y nutrias. De igual modo, cabe mencionar la existencia de topónimos que recuerdan la presencia de William Low, evidencia de sus incursiones por los litorales del sur de Chile $e^{2}$.

\section{Actividades de William Low}

en los mares australes

La presencia de loberos en latitudes australes data desde fines del siglo XVIII. Determinar

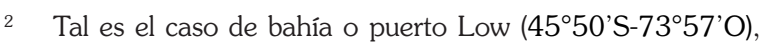
situada en la costa norte de la isla Gran Guayteca y el puerto homónimo, situado al oeste de la mencionada bahía, ambos lugares localizados al sur de la isla de Chiloé y que forman parte de la Región de Aysén del General Carlos Ibáñez del Campo. Otro topónimo es Punta Low (5244'S-7042'O), localizado en la costa nororiental del Estrecho de Magallanes.

3 Desde la isla Alejandro Selkrik (mejor conocida por los loberos como Masafuera), se estima que desde 1792, cuando se reporta al primer lobero yankee cazando allí (capitán Stewart, a bordo del 'Eliza'), hasta 1807, año en que las recaladas loberas cesan producto de la dramática con exactitud la fecha de llegada de la primera embarcación con fines de caza de lobos marinos al extremo sur americano, resulta una tarea compleja sino imposible, dada la escasez de registros que lo consignen, situación que responde en parte, a la naturaleza misma de la actividad, por cuanto una vez descubierta alguna lobería por parte de alguna tripulación, se hacía necesario mantener en secreto su ubicación (Kirker, 1970, p. 21). Algunos autores señalan que fueron los británicos los que primeramente llegaron a cazar lobos marinos a esta parte del globo (Busch, 1985, pp. 9-10; Mill, 1905, pp. 87-88; Pereira, 1971, pp. 50-51), en tanto que otros, refieren que fueron los marineros yankees quienes los antecedieron (Berguño, 1993, p. 7; Jones, 1981, p. 254; Kirker, 1970, pp. 3-7).

Como sea, lo cierto es que desde la segunda mitad de la década del setenta del siglo XVIII, comienza la primera gran oleada de cazadores de pinnípedos, la que se vería interrumpida por la guerra anglo-estadounidense de 1812 (que afectaría en particular a las naves estadounidenses) y más tarde, desde 1819 (año del descubrimiento de las islas Shetlands del Sur) y por un lapso de poco más de veinte años se retoma la actividad con nuevos bríos, para declinar en la medida que las poblaciones de pinnípedos fueron disminuyendo drásticamente producto de la caza indiscriminada ${ }^{3}$. Años más tarde, a contar de 1860, con el desenvolvimiento de la colonia de Punta Arenas, la caza de lobos marinos volverá a adquirir importancia, para declinar durante la segunda década de la siguiente centuria (Martinic, 1973, pp. 8-11), no sólo en lo tocante al área archipielágica de Patagonia y Tierra del Fuego, ya que en las islas Falkland y subantárticas, la importancia de la actividad decrece a contar de la segunda mitad del siglo XIX (Dickinson, 2007, p. 16).

disminución del número de otáridos, se extrajeron más de 3.500.000 pieles (Clark, 1884, p. 407). El explorador y lobero británico James Weddell, que efectuara sucesivos viajes a los mares australes entre los años 1819 y 1824, estimó la cantidad de lobos finos capturados en las islas Shetland del Sur entre los años 1821 y 1822 fue de aproximadamente de 320.000 ejemplares, además de 940 toneladas de aceite de elefantes marinos, en tanto que desde las islas Georgias del Sur se extrajeron alrededor de 1.200 .000 pieles (Weddell, 1825, pp. 54, 55, 141). No existen datos ni estimaciones respecto de las capturas de pinnípedos en el área de Patagonia y Tierra del Fuego. 
Todo apunta a que es dentro de la segunda oleada de sealers (loberos), que William Low hace su aparición por los mares australes, siendo el foco inicial de sus actividades, el área correspondiente al archipiélago de las islas Falkland. Lo anterior a partir de información localizada en distintas fuentes, una de las que señala que el capitán William Low zarpó el 3 de agosto de 1822 desde el Río de la Plata, con destino a las islas Falkland a bordo del bergantín Adeona 4 (Lorton, 2012 p. 119). De acuerdo al registro de buques del Lloyds Register $^{5}$, en su edición del 1 de agosto de 1823 , el Adeona arribó a Liverpool el 29 de julio de aquel año, procedente de Buenos Aires, desde donde había zarpado el 6 de mayo de 1823. Lo anterior se complementa con la valiosa recopilación hecha por A.G.E. Jones, respecto del listado de embarcaciones británicas que participaron en las pesquerías de los mares del sur entre 1775-1859, a partir de los registros de la Society of Merchants ${ }^{6}$ y Lloyds Register, donde se apunta que Low llega a las Falkland el 5 de febrero de 1823, alcanzando el puerto de Liverpool a fines de julio del mismo año, con 3.807 pieles de lobos marinos (Jones, 1992, p. 41).

A partir de aquel año, es posible encontrar en repetidas oportunidades el nombre de William Low, no sólo como capitán del mencionado bergantín Adeona, de 142 toneladas y construido en Quebec (Jones, 1992, p. 40), sino que también de otras embarcaciones, a saber, el sloop (balandra) Dart y el cutter (cúter) Uxbridge. Las informaciones contenidas en el diario de navegación publicado tras el término de la expedición científica organizada por el Almirantazgo Británico y que se llevó a cabo entre 1826 y 1834 bajo el mando de los capitanes Philip Parker King y Robert Fitz Roy, ratifican lo anterior y entregan, además, información que permiten reconstruir en parte el quehacer de este marino británico, por ejemplo,

4 Adeona, es el nombre de una deidad romana a quien se le atribuía la facultad de permitir el regreso a casa de los viajeros (Secchi, 2007, p. 11).

5 Publicación periódica editada en Londres, que desde 1734 publica información referida a la entrada y salida de embarcaciones, desde los principales puertos británicos y con posterioridad, se incluyó información de otros puertos del mundo.

6 Este registro surgió como competencia del Lloyd List, iniciando su circulación en el año 1800.

La isla Noir (5430'S-7300'O), se encuentra ubicada al que a las embarcaciones señaladas, se suman otras dos, el Mercury (las fuentes no dan cuenta del tipo de embarcación a la que corespondería) y el schooner (goleta) Unicorn.

En cuanto al Uxbridge, registra actividad desde 1826 hasta 1831, con William Low como capitán, todos con destino a los mares del sur, zarpando -de acuerdo al Lloyds Register- desde el puerto escocés de Greenock (Jones, 1991). Parker King proporciona varias referencias que sitúan a Low a bordo del cúter, en compañía del bergantín Adeona y del Mercury, para las temporadas de caza de 1827 y 1828, que como se verá más adelante, dan cuenta de incursiones a lugares tan apartados e inaccesibles como la isla Noir ${ }^{7}$, y de habituales recorridos por el estrecho de Magallanes y las islas Falkland. A pesar de las escuetas referencias que dejaban los capitanes respecto de los lugares a los que se dirigían, donde por lo general solamente informaban como destino 'mares del sur', lo que sumado a la falta de bitácoras, como en este caso, dificulta saber con mayor precisión detalles de las actividades de estos intrépidos marineros. Igualmente ha sido posible encontrar referencias en fuentes chilenas que complementan las informaciones de los documentos aludidos en los párrafos precedentes. Tal es el caso de los registros de entrada y salida de embarcaciones de la capitanía de puerto de Valparaíso, donde el día 10 de septiembre de 1826, se informa la llegada del cúter de 91 toneladas y de nacionalidad inglesa, Uxbridge, capitán Low, con una tripulación de 16 personas y un pasajero, procedente de la isla de Chiloé desde donde arribó con seis días de navegación, informando como cargamento 'cueros de lobos'. Cinco días más tarde, se registra la salida de la embarcación, esta vez con sólo 10 tripulantes e informando como destino 'a su pesca'9. Este registro, resulta ser el primero que deja de manifiesto la temprana

oeste del archipiélago de la Tierra del Fuego, frente a la Península de Brecknock (Risopatrón, 1924, p. 590).

8 South Seas (SS), es la inscripción genérica contenida en la mayoría de los registros, así como también Southern Fishery (SF), y en otras oportunidades figuran algunas más específicas, tales como, Falkland, Magellan Strait, Patagonia, Tierra del Fuego y South Shetland.

9 Archivo Nacional Histórico de Chile, Fondo Ministerio de Marina, Volumen 31, sin foliar, planillas 10/09/1826 y 25/09/1826 
relación de William Low con la isla de Chiloé, lugar donde años más tarde se radicará. Igualmente ratifica que la mención "mares del sur" informada por los capitanes, efectivamente abarcaba una amplitud geográfica como lo sugiere tan genérica denominación, inclusive en el año 1827 se registra a W. Low y el Uxbridge en las islas Ascensión y Santa Helena, en el océano Atlántico (Jones, 1986, p. 83), en tanto que Fitz Roy sitúa a W. Low en las islas Galápagos, según se desprende de la siguiente mención, datada septiembre de 1835 en el contexto de un recorrido exploratorio en la isla San Cristóbal (llamada anteriormente Chatham por los marinos ingleses) del archipiélago:

[...] At noon, seeing a small cove, I went in a boat to examine it, and look for water. We found no signs of any in that place; but a little farther west, a fine stream was seen falling from a lava cliff, about thirty feet high. Mr. Low had described this waterfall correctly; and his account of the watering place near it was soon verified, by our discovering a cove half a mile to the westward of the cascade $[\ldots]^{10}$. (Fitz Roy, 1839a, p. 488).

Las islas Galápagos, fueron visitadas desde fines del siglo XVIII y durante la centuria siguiente por balleneros y loberos, y a pesar de la presencia de lobos marinos en el archipiélago, los que igualmente fueron cazados, pero dado que su población no representaba un número tal que justificase expediciones a tan remoto lugar, los principales atractivos de estas islas estuvieron dados por la presencia de las tortugas gigantes (que proveían de carne fresca y nutrientes para combatir el escorbuto) y suministros de agua fresca. Tras renovar suministros, las expediciones loberas seguían su ruta hacia el puerto de Cantón, o bien, retornaban a la costa oeste de América del Sur para continuar con sus actividades cinegéticas (Kirker, 1970, pp. 95-99). Se incluye esta digresión, con

10 Al mediodía al ver una pequeña caleta, fui en un bote a examinarla, y buscar agua. No encontramos ningunas señales en aquel lugar; pero un poco más al oeste, un delgado torrente fue visto cayendo desde un acantilado de lava, de cerca de 30 pies de altura. Mr. Low habia descrito correctamente esta cascada; y su informe de un lugar de aguada en las cercanías el fin de explicar la presencia de W. Low en tan alejadas latitudes.

Respecto del sloop Dart, embarcación de 86 toneladas y construido en Liverpool en el año 1818, figura bajo la capitanía de William Low y como propietario un tal L. Low, desde 1823 a 1825, zarpando desde Liverpool hacia los mares del sur, por lo que habría trabajado en compañía del Adeona; en años posteriores se registran diferentes capitanes (Jones, 1991, 1992), lo que sugiere que la embarcación dejó de pertenecer a la flotilla Low, por cuanto desde 1826 entra en escena el Uxbridge y en 1829 el Mercury, como acompañantes del bergantín Adeona.

Desde 1829 se conoce la existencia de una tercera embarcación asociada a Low, el Mercury, que aparece mencionado por Parker King como parte de la flotilla que en dicho año recorrió las costas patagónicas y las islas Falkland, ya que acompañaba al Adeona y al Uxbridge. Informa además, que al mando de esta embarcación, William Low fue uno de los primeros en haber navegado el canal Cockburn (ver Fig. 3), con posterioridad al recorrido de este canal por parte de la tripulación de la goleta lobera inglesa Prince of Saxe Coburg, que al mando de Matthew Brisbane, naufragó en las cercanías del canal Bárbara, en diciembre de 1826 (Parker King, 1829, pp. 66, 254). Cabe consignar que no existe registro de salida o entrada de esta embarcación en las fuentes compulsadas, pues únicamente figura en una base de datos hecha a partir de la sección de "noticias marinas del Lloyd's List", donde para los meses de marzo, septiembre y noviembre de 1830 el Mercury aparece asociado al apellido Low ${ }^{11}$. A modo de explicación, la escasa presencia en los registros de esta embarcación, puede responder a que el Mercury haya sido una embarcación menor, ya sea un sloop (balandra) o un whale-boat (bote ballenero), naves que debido a su mayor movilidad, eran utilizadas en los cruceros loberos en las maniobras de acercamiento a los apostaderos de pinnípedos, las que resultaban ser menos riesgosas que realizar dicha tarea con embarcaciones de mayor tonelaje. Lo

fue prontamente verificado, debido a nuestro descubrimiento de una caleta a media milla al oeste de la cascada.

11 'Lloyd's List marine news 1740 - 1837'. [en línea]. Londres: City of London Corporation. Disponible en: <https:// www.cityoflondon.gov.uk/lloydsList/search.aspx> [2014, Febrero 20] 
anterior es coherente con lo observado en logbooks o bitácoras de capitanes loberos estadounidenses, donde solamente informaban el nombre de la embarcación principal, tanto al momento de zarpe y arribo, sin embargo, en el contexto de la narración se registra la presencia de embarcaciones menores, por lo general botes balleneros, y como en el caso del viaje del bergantín Betsey entre 1842-1844, al mando del capitán Stephen Perkins, menciona en su relato la utilización de tres botes, uno de ellos llamado Dingy ${ }^{12}$.

Volviendo al Adeona, los registros dan cuenta de varios viajes a los mares del sur desde 1822 en adelante. Los registros de los años 1825, 1826 y 1827, indican como capitán del bergantín a Andrew Low, todos partiendo desde el puerto de Greenock y con destino a los mares del sur (SS), en tanto que los registros de 1829 (procedente desde las Falkland, desde donde zarpó el 8 de mayo de 1829, arribando a Liverpool el 8 de febrero de 1830); 1830 (saliendo desde Greenock con destino a SS); 1831 (ídem 1830) y 1832 (saliendo desde Greenock con destino a Southern Fishery, SF), muestran como capitán a William Low (Jones, 1991). Cabe entonces preguntar ¿Quién es Andrew Low? La respuesta deriva de un par de informaciones fragmentarias, que se encuentran en el Volumen I correspondiente a la primera parte de la expedición británica llevada a cabo entre 18261830 bajo el comando de Philip Parker King y donde se consigna lo siguiente:

Before daylight on the 14th I was informed that the Beagle was seen in the offing. Blue lights were burnt, and lanterns immediately shown to guide her to the anchorage; but our disappointment was great when the stranger proved to be Mr. W. Low's schooner, the Uxbridge. He had been sealing since November in the neighbourhood of

12 Logbook of the Betsey (Log 7), G. W. Blunt White Library, Mystic Seaport Museum, Inc.

13 El 14, antes de amanecer, se me informó que se había visto a la Beagle en el horizonte. Se quemaron luces azules, e inmediatamente se mostraron faroles para guiarla al fondeadero; peros nuestra desilusión fue grande cuando el desconocido resultó ser la goleta de Mr. W. Low, el Uxbridge. Había andado cazando lobos desde noviembre en las cercanías de la isla Noir, cerca de la entrada exterior del canal Bárbara, y estaba en camino a cabo Gregorio para reunirse con su hermano mayor,
Noir Island, near the outer entrance of the Barbara Channel, and was on his way to Cape Gregory to meet his elder brother, who had been collecting sea-elephant oil at South Shetland (Parker King, 1839, p. 119) ${ }^{13}$.

Lo anterior ocurrió el 14 de enero de 1828, fecha que en la tripulación del Adelaide (goleta auxiliar de la expedición británica) se encontraba surta en la bahía de San Juan (estrecho de Magallanes), y nos muestra que William Low tenía un hermano mayor y, que en asociación con aquel, realizaron expediciones de caza de lobos marinos y obtención de aceite. Antes, el 17 de agosto de 1827 Andrew Low había zarpado desde Greenock con rumbo a los mares del sur (SS), y como se ha podido consignar, los apostaderos en torno a los cuales efectuaban sus expediciones cinegéticas, abarcaban una vasta área geográfica, recorriendo desde las Falkland, pasando por el estrecho de Magallanes y canales adyacentes, hasta tocar incluso las costas de las islas antárticas de las Shetland del Sur. Precisamente, fue desde alguna de las islas de aquel archipiélago, que a inicios del año de 1828, Andrew Low arribó de una larga y ardua travesía en busca de elefantes marinos, y tan severa debió ser la temporada, ya que se reporta su fallecimiento el 14 de junio de 1828 , víctima de escorbuto:

The severity of the weather brought a most disagreeable accompaniment. Scurvy appeared, and increased; while the accidental death of a seaman, occasioned by falling down a hatchway, followed by the decease of two others, and also of Mr. Low, of the Adeona, whose body was brought to me for burial, tended to create a despondency amongst the crew that I could in no way check (Parker King, 1839a, p. 144) ${ }^{14}$.

quien había estado cogiendo aceite de elefante marino en las Shetland del Sur.

14 La severidad del tiempo trajo un acompañamiento más desagradable. Hizo su aparición el escorbuto, y ha aumentando; aunque la muerte accidental de un marinero, ocasionada por caer una escotilla, seguida del deceso de dos más, y también del de Mr. Low, de la Adeona, cuyo cuerpo se me trajo para sepultarlo, tienden a crear desaliento entre la tripulación engendraron entre la tripulación lo que de manera alguna podía controlar. 
La información aportada por Parker King, transcurre en la bahía San Juan ${ }^{15}$, lugar donde la expedición británica instaló su base de operaciones en aquella campaña hidrográfica, y en cuyas cercanías establecieron un cementerio, donde sepultaron entre otros, al comandante Pringles Stokes (fallecido el 12 de agosto de 1828), razón por la cual, resulta plausible sugerir, que el cuerpo de Andrew Low yace en aquel sitio ${ }^{16}$.

Antes de informar la muerte del hermano mayor de los Low, y a días de que se produjera el avistamiento del Uxbridge en la bahía de San Juan, Parker King refiere que tras salir desde Río Gallegos a bordo del bergantín Beagle, el día 23 de enero se encuentran con el Adeona en las cercanías de la Primera Angostura, en la costa nororiental del Estrecho de Magallanes, bergantín que venía de su expedición a las Shetlands del Sur, con el fin de reunirse con la tripulación de la Uxbridge (Parker King, 1839, p. 121). A los pocos días los hermanos Low se reunieron $y$ fueron avistados el 2 de marzo, mientras se dirigían a procesar la grasa obtenida de los elefantes y lobos marinos para obtener aceite, siendo la idea original llevar a cabo dicho proceso en el puerto San Antonio ${ }^{17}$, lo que finalmente realizan en puerto Bougainville ${ }^{18}$ o puerto Jack (denominado así por los loberos), a instancias de Parker King, quien les manifiesta que este lugar posee mayor resguardo de las inclemencias del tiempo (Parker King, 1839, p. 122). Hacia fines de abril, Andrew Low permanecía en puerto Bougainville, donde fue visitado por una parcialidad de aborígenes kawésqar, a los que no les permitió abordar su bergantín. Esta referencia resultaría ser la última que muestra al hermano de

15 Port Famine, según los británicos, en la errónea creencia de que en aquella bahía habría estado emplazada la malograda ciudad fundada por Pedro Sarmiento de Gamboa en el año 1584, Ciudad del Rey Don Felipe y que la posteridad, se conocería como Puerto del Hambre. Finalmente, en 1955 se encontró el verdadero emplazamiento de la ciudad fundada por el español, específicamente poco más al norte de la punta Santa Ana -accidente geográfico donde en 1843 se funda el Fuerte Bulnes- ,en una pequeña bahía llamada Buena.

16 En la actualidad aquel sitio es conocido como Cementerio de los Ingleses, y se localiza en la costa de la bahía de San Juan, en el Estrecho de Magallanes, aproximadamente a 60 kms. al sur de la ciudad de Punta Arenas.

17 Puerto San Antonio (53 $\left.55^{\prime} \mathrm{S}-70^{\circ} 52^{\prime} \mathrm{O}\right)$, en la costa oeste de la isla Dawson. (Risopatrón, 1924, p. 795).

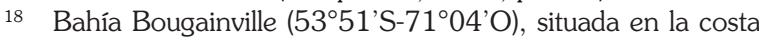

William Low con vida, ya que la siguiente alusión, corresponde a aquella en que se da cuenta de su fallecimiento a mediados de junio.

La muerte del hermano mayor, debió de golpear con fuerza el ánimo de William Low, por cuanto el 30 de Junio, reúne a su pequeña flotilla compuesta por el Adeona (ahora sin su capitán original), el Mercury y el Uxbridge y zarpan con destino a las islas Falkland, para desde aquí enfilar rumbo a Gran Bretaña. De hecho, el 14 de marzo de 1829 ingresaba al puerto de Greenock, en el río Clyde, el cutter Uxbridge, al mando del capitán Wyllie, quien seguramente reemplazó a William Low en el mando de esta embarcación, dado que este último arribó a Londres el 8 de mayo a bordo del Adeona (Jones, 1986, pp. 86-87). Como se lee, la muerte del hermano mayor de William, no sólo provocó cambios en las tripulaciones, sino que debió significar el motivo principal de la partida desde el estrecho de Magallanes con rumbo al Atlántico norte.

Posteriormente, en los años 1830, 1831 y 1832, el Adeona retorna a los mares del sur, procedente de Greenock y los registros muestran como capitán a William Low, en tanto que como propietario sigue figurando Andrew Low ${ }^{19}$. El penúltimo crucero lobero del Adeona sería el realizado tras su zarpe desde Liverpool en febrero de 1831 con destino al estrecho de Magallanes, lugar donde arriba en agosto, tras una escala previa en Montevideo. El último viaje hacia las pesquerías australes, figura en el año 1832, zarpando desde Greenock. Este mismo año, el bergantín fue desmantelado en el puerto de Montevideo (Jones, 1993, p. 25; 1991, p. 139; 1992, p. 42).

sureste de la península de Brunswick (Risopatrón, 1924, p. 88).

19 De acuerdo a Jones (1986, x-xi; 1993, 18-19), muchas veces los lugares de zarpe y destino de las embarcaciones, así como también aquellos donde se consignaba la información referida a sus características (tipo de embarcación, tonelaje, condición, lugar de construcción, etc.), presentan inconsistencias en los datos, por cuanto en ocasiones, verbigracia, se reportaba en el Lloyds List el nombre de un determinado capitán y de su respectivo propietario, en tanto que en el listado de la Society of Merchants, dicha información aparece intercambiada, o simplemente la información se encuentra sólo en uno de estos dos registros $\mathrm{y}$, por otro lado, la información no era actualizada por parte de los propios capitanes o socios propietarios de las naves. 
Respecto de este último antecedente, valga mencionar que hacia fines del siglo XVIII Montevideo adquirió relevancia como puerto, pasando a rivalizar con el de Buenos Aires, en particular, cuando en 1776 las autoridades imperiales españolas crearon el Apostadero de Montevideo, hecho que trajo como consecuencia que las embarcaciones destinadas a salvaguardar la soberanía de la corona española en lugares como la Patagonia e islas Falkland zarparan desde Montevideo. En términos geográficos, la condición de fondeadero natural, que permitía barcos de mayor calado, transformó a este puerto en una importante puerto de recalada para las embarcaciones que viajaban desde Europa hacia el Pacífico, donde por cierto, igualmente ingresaban gran cantidad de barcos balleneros y loberos (Caviglia, 2012, p. 127). Ante esta situación, resulta fácil comprender la presencia no sólo de Low en las costas del río de La Plata, ya que estos puertos, juntos con el de Río de Janeiro, eran sitios de recalada obligada para la obtención de suministros por parte de balleneros y loberos antes de seguir camino a las pesquerías de los mares del sur.

Justamente a contar de 1832 y tras la baja del Adeona en Montevideo, se registra por primera vez la presencia de la goleta Unicorn con William Low a su mando. Un examen detallado de las fuentes nos aporta una serie de informaciones que permiten reconstruir el itinerario de este lobero británico tras embarcarse en el Unicorn y hasta su muerte acaecida en 1841 en un lugar indeterminado de la isla de Chiloé.

En marzo de 1833, Robert Fitz Roy informa que se encuentra con "Mr. William Low" en Puerto Luis (East Falkland o isla Soledad), quien retornaba después de seis meses de cazar lobos marinos en la costa occidental de Patagonia, quien le informa de lo desastroso que resultó ser este viaje, producto de una sucesión de vendavales que arreciaron durante sesenta y siete días y que en los veinte de años de experiencia no le había tocado experimentar tan adversas condiciones climáticas. Como resultado,

20 Difícilmente podría haber encontrado una embarcación más apta, con ciento setenta toneladas de porte, armado en roble y forrado completamente en cobre, muy espacioso, buen velamen, extremadamente maniobrable y un barco de primer nivel [...]. Transcurridos unos cuantos días, en los cuales fue muy cuidadosamente examinada por Mr. Bray, y toda volvió con su embarcación seriamente dañada y con las bodegas vacías. Esta embarcación, en la que Low había empleado todos sus recursos, era la goleta Unicorn, en la que además de oficiar de capitán, era socio propietario junto con otros personajes con asiento en Montevideo (Fitz Roy, 1839a, p. 273). Como se indicó más atrás, el Adeona realiza su último viaje en 1832, para luego terminar su vida útil en el citado puerto, razón por la cual, y de acuerdo a los datos de que se disponen, se deduce que tras la venta de su antiguo bergantín, Low y sus socios compran una nueva goleta en el mes de septiembre de 1832, y tras efectuarle los correspondientes arreglos, se dirige con el Unicorn desde Montevideo hacia la Patagonia, a lo que finalmente sería su último crucero lobero.

Para aquel entonces, la expedición británica a bordo de la Beagle, precisaba de una embarcación auxiliar que les permitiera completar sus exploraciones, y en tal sentido Fitz Roy consideró la idea de adquirir la Unicorn, y respecto de sus características y de los detalles de la operación de compraventa, hizo los siguientes comentarios:

A fitter vessel I could hardly have met with, one hundred and seventy tons burthen, oak built, and copper fastened throughout, very roomy, a good sailer, extremely handy, and a first-rate sea-boat [...]. A few days elapsed, in which she was surveyed very carefully by Mr. May, and my mind fully made up, before I decided to buy her, and I then agreed to give six thousand dollars (nearly £1,300) for immediate possession. Being part owner, and authorized by the other owners to do as he thought best with the vessel in case of failure, Mr. Low sold her to me, payment to be made into his partners' hands at Monte Video ${ }^{20}$ (Fitz Roy, 1839a, p. 274).

Según se desprende de la cita precedente,

vez que me decidí a comprarla, y entonces acordé entregar seis mil dólares (casi 1300£) por su posesión inmediata. Siendo socio propietario, y autorizado por los demás dueños para hacer lo que estimase conveniente con la embarcación en caso de fracaso, Mr. Low me la vendió, efectuando el pago en manos de sus socios en Montevideo. 
William Low se había asociado con otros armadores de la ciudad de Montevideo para la adquisición de la goleta Unicorn, situación que debió estar influenciada en parte, por la muerte de su socio y hermano Andrew Low cuatro años antes, y por la sucesiva desaparición de sus demás embarcaciones, ya que finalmente se registra únicamente como propietario del bergantín Adeona, lo que hace presumir que tras el viaje realizado en 1832 en esta última embarcación, y teniendo en cuenta su antigüedad y el maltrato al que habría sido sometida, debió forzosamente desprenderse del bergantín que antes formó parte de la flotilla que comandaban y regentaban junto a su hermano mayor, y muy probablemente, con la participación del padre de los Low.

Se apunta lo anterior, en función de un dato que tangencialmente proporciona Fitz Roy, cuando refiere algunas características de su personalidad: Mr. William Low is the son of a respectable land-agent in Scotland; he was brought up as a sailor, and possesses strong common sense, quick apprehension, a readiness at description, and an extraordinary

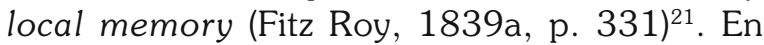
este sentido, resulta plausible inferir que el padre igualmente pudo participar en el negocio de la caza de lobos junto a sus hijos, máxime si se tiene en cuenta el antecedente que para los casos del cutter Uxbridge y del sloop Dart, figura como propietario un tal L. Low, que bien podría corresponder al progenitor de William y Andrew. También se puede afirmar que William Low y familia son oriundos de Escocia, lo que coincide con los registros que dan cuenta de sucesivos zarpes y llegadas desde y hacia Greenock, y como se señaló anteriormente, corresponde a un puerto ubicado en la desembocadura del río Clyde, en la costa oeste de Escocia.

21 Traducción: Mr. Low es hijo de un respetable agente inmobiliario de Escocia; fue criado como marinero, posee un gran sentido común, ágil comprensión, facilidad de descripción y una extraordinario memoria local.

22 El nombre fue dado en recuerdo de la embarcación que había formado parte de la primera etapa de exploración de las marinos británicos llevada a cabo entre los años de 1826-1830, bajo el comando de Philip Parker King.

23 Thomas Cocharne participó en la Guerra de independencia de Grecia que se desarrollo entre los años
Más adelante en su relato, Fitz Roy refiere otros interesantes detalles respecto de la Unicorn, -a la que rebautizó con el nombre de Adventure ${ }^{22}$, entre los que destacan que la goleta fue construida como yate en Rochester (Inglaterra) por un costo de $£ 6000$, para posteriormente ser reacondicionada y pasar a ser utilizada en el Mediterráneo bajo el mando de Thomas Cochrane ${ }^{23}$; años después fue preparada para participar en las operaciones que buscaban poner fin al bloqueo de Buenos Aires ${ }^{24}$, sin embargo, la nave fue apresada por las fuerzas brasileñas y llevada a Montevideo, donde fue adquirida por el cónsul británico, quien finalmente la acondicionó para ser utilizada en la caza de otáridos (Fitz Roy, 1839a, p. 275). Resulta entonces que tras la mencionada adquisición, se habría generado la asociación de William Low con Samuel Hood (cónsul británico) y otros accionistas, motivada con el fin de compartir los beneficios y los riesgos de una actividad mercantil tan riesgosa, no sólo por ser llevada a cabo en latitudes alejadas y a merced de las condiciones climáticas, sino que también, producto de la incertidumbre de hallar la cantidad de presas necesarias para hacer rentable el viaje. Nótese que los socios de Low le autorizan a realizar lo que estimase pertinente "en caso de fracaso", instrucción que al cabo resultó un presagio de lo que habría de suceder meses más tarde.

No se conocen registros gráficos de las embarcaciones que formaron parte de la flotilla de William Low. Sin embargo, gracias a la venta forzosa que William Low debió efectuar de la goleta Unicorn en marzo de 1833, se ha podido dar con dos acuarelas, un boceto y una ilustración, que muestran esta embarcación una vez que pasó a formar parte de la expedición hidrográfica llevada a cabo bajo el comando de Robert Fitz Roy, de las cuales se trata a continuación ${ }^{25}$. La autoría de las imágenes corresponden al artista Conrad Martens, quien formó parte de la tripulación del Beagle

1826-1828 y, efectivamente, entre 1826 y 1827 estuvo al mando del yate Unicorn (Cordingly, 2008, pp. 322323).

24 Se refiere al bloqueo de Buenos Aires por parte del Imperio del Brasil, llevado a cabo entre 1825-1828.

25 Las otras 2 imágenes aludidas corresponden a "Point Arenas, isla de Cochinos, at Chiloé" (Disponible en: http://cudl.lib.cam.ac.uk/view/MS-ADD-07984/31) y "Anchorage, and spanish ruins, Port Desire" (Disponible en Fitz Roy, 1839a, p. 316). 


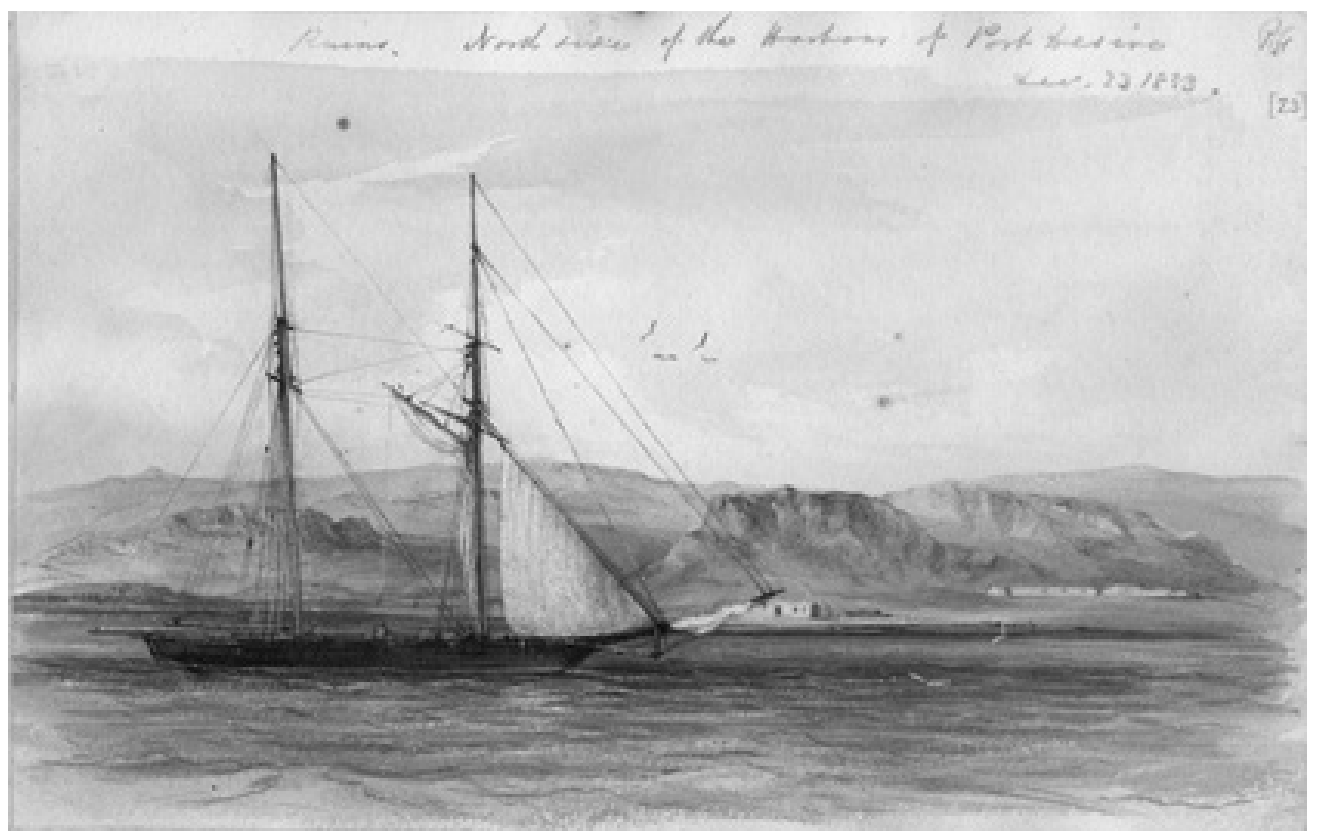

Fig. 1. "Ruins. Nort side of the Harbour of Port Desire".

Fuente: Martens, C. 1833-1834. Sketchbook III. Cambridge University Press, p. 29.

Disponible en: http://cudl.lib.cam.ac.uk/view/MS-ADD-07983/29

entre 1833 y 1834. En la Fig. 1, se aprecian al fondo las ruinas de Puerto Deseado ${ }^{26}$, donde se observan la Beagle y Adventure (bautizada así, tras adquirir la Unicorn) llegan el 23 de diciembre de 1833 provenientes de Montevideo, y en primer plano, la Adventure (anteriormente Unicorn), apreciándose detalles de sus aparejos y mástiles. La acuarela muestra que la embarcación era de color negro y sus mástiles marrón (por razones técnicas se incluye aquí la imagen en blanco y negro). Dado el ángulo de visión, la acuarela debió ser realizada por Martens a bordo de la Beagle. La imagen aparece con la siguiente inscripción: "Ruins. Nort side of the Harbour of Port Desire. Dec. 23 1833".

En cuanto a la acuarela de la Fig. 2, titulada "Slinging the monkey", se aprecia al lado derecho a la Beagle, con sus tres mástiles, uno de los cuáles le fue añadido una vez que fue comisionado para participar en el levantamiento de las costas sudamericanas. A su lado, la embarcación que perteneciera a Low,

26 Puerto Deseado $\left(47^{\circ} 45^{\prime} \mathrm{S}-65^{\circ} 55^{\prime} \mathrm{O}\right)$, se localiza en la costa oriental de la Patagonia. En 1790, bajo el reinado del Rey Carlos IV, se crea la Real Compañía Marítima de Pesca, cuyo objetivo principal, era el aprovechamiento de cetáceos, pinnípedos, y pesca de altura en general, que a diferencia del bergantín, estaba equipada con dos mástiles, tal como es el caso de la generalidad de las goletas. La imagen aparece fechada un 25 de diciembre de 1833, día en que los marinos británicos llevaron a cabo una alegre celebración de Navidad (Fitz Roy, 1839a, p. 316).

\section{Consideraciones sobre las operaciones loberas}

Llegado este punto, y a la luz de los antecedentes hasta aquí expuestos, se pueden realizar algunas extrapolaciones respecto de la dinámica mercantil de las operaciones loberas llevadas a cabo por William Low, analizadas desde una escala de análisis particular o micro, $y$ en este sentido, al ser trasladadas a una escala de observación global, permiten establecer un marco respecto del quehacer de otros sealers de los que únicamente se conocen sus apellidos y la denominación de sus embarcaciones. Precisamente

en la costa de Patagonia (Fernández \& Martinez, 1991). El mismo año de su creación, se creó una factoría y un fuerte (ruinas que se aprecian en las Figs. 1 y 2), instalaciones que a la sazón, serían abandonadas en 1807. 
el historiador británico A.G.E. Jones reflexionaba respecto del anonimato de muchos de quienes participaron en esta actividad mercantil, incluyendo a Low, de quien señalaba que sus actividades cinegéticas se habrían extendido entre 1820-25.

En el caso de William Low, se ha podido establecer que además de capitanear sus embarcaciones, era igualmente propietario, en un primer momento en sociedad con su hermano Andrew Low y, eventualmente con su padre, llegando a poseer tres veleros simultáneamente. Sin embargo de lo anterior, probablemente en sus inicios como cazador de mamíferos marinos Low es posible que haya sido miembro de alguna tripulación, y conforme el paso de los años fue acumulando experiencia y el capital necesario para adquirir una embarcación de mayor porte. Tal es el caso de la propiedad del bergantín Adeona. Si bien los registros lo muestran como capitán a contar del año 1822, William Low le comenta a Fitz Roy en marzo de 1833, que nunca en sus más de veinte años de experiencia le había tocado soportar tan rigurosas condiciones climáticas, lo que sugiere que por lo menos desde 1813 se habría dedicado a este tipo de actividad. En un contexto general, Jones (1981) refiere que la actividad de caza de lobos marinos fue llevada a cabo fundamentalmente por pequeños propietarios, donde más de la mitad de ellos poseía sólo una embarcación, en contraste con los grandes armadores que poseían cinco o más naves, destacando entre estos últimos, las firmas Bennett y Enderby, que en 1821 poseían respectivamente, 26 y 14 embarcaciones (p. 263264).

Los registros compulsados, dan cuenta de un constante recambio de las embarcaciones de la flotilla Low. En el año 1822 inician sus actividades con el bergantín Adeona (142 tons), cuya vida útil se extendió hasta 1832. Aunque al principio la propiedad de esta embarcación figura bajo el nombre de Thomas Brassey, quien la adquiere el 7 enero 1822 en Greenock y el mismo día la vende a unos comerciantes de la misma ciudad, cuatro años más tarde Andrew Low se convierte en su dueño (Jones, 1992, p. 40). Esta situación se corresponde con lo apuntado en el párrafo anterior, en cuanto a que en un primer momento algunos loberos fueron capitanes o miembros de la tripulación, y gracias a las ganancias obtenidas pudieron hacerse de sus propias embarcaciones, en este caso particular, de un bergantín de 142 tons; paralelamente entra en escena el sloop Dart (86 tons), figurando con

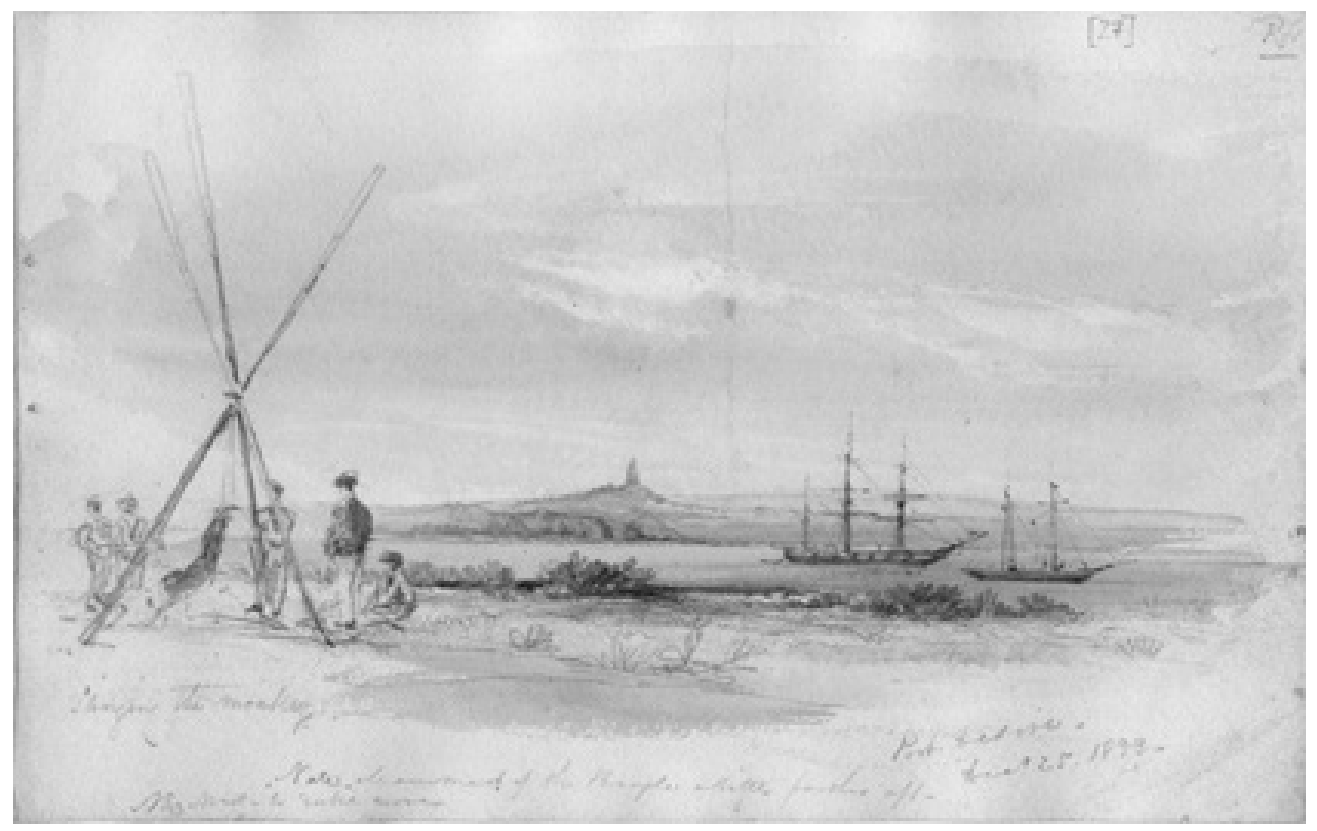

Fig. 2. "Slinging the monkey".

Fuente: Martens, C. 1833-1834. Sketchbook III. Cambridge University Press, p. 35. Disponible en: http://cudl.lib.cam.ac.uk/view/MS-ADD-07983/35 
actividad entre 1823 y 1825 , para luego pasar a manos de otro propietario; en 1826 se incorpora como acompañante del Adeona, el cúter Uxbridge (91 tons), desempeñándose en los mares del sur entre los años 1826-1831; entre 1829-1830 figura la embarcación menor llamada Mercury; y finalmente, hacia la segunda mitad del año 1832 y hasta marzo de 1833, Low aparece con una nueva embarcación, la goleta Unicorn (170 tons), embarcación de mayor porte de las hasta ahí utilizadas por este lobero escocés, en la que participó de su propiedad junto con otros socios asentados en Montevideo.

Según apunta Dickinson (2007), entre 1819-1826, periodo de creciente organización de expediciones loberas, debido al descubrimiento del archipiélago de las Shetland del Sur, el promedio de tonelaje de las embarcaciones era de 195 tons, en contraste con las 400 tons que promediaron los navíos balleneros que entre 1786 y 1819 se dirigieron hacia latitudes australes. Conforme pasaron los años, el tonelaje de las embarcaciones fue disminuyendo como consecuencia de la declinación de las poblaciones de lobos y elefantes marinos, situación que llevaba a los loberos a realizar viajes más largos y a lugares cada vez más inaccesibles, donde resultaba necesario la utilización de embarcaciones más pequeñas y maniobrables, razón por la cual muchos de quienes participaron en esta actividad no estaban dispuestos a arriesgarse utilizando barcos de primera clase, y por lo general, se acondicionaban navíos cuya antigüedad era considerable (p. 11-12). Esta situación explica los constantes naufragios que se reportaban en los mares del sur, no sólo por las conocidas condiciones meteorológicas del área, sino que también, por las embarcaciones que se utilizaban, que en su gran mayoría poseían un largo recorrido previo, e igualmente, correspondían a navíos de mayor maniobrabilidad, pero de menor tonelaje y calado, lo que las hacía presa de las constantes tormentas o los williwaws como le denominaban los tripulantes de las embarcaciones loberas a las repentinas ráfagas de viento que continuamente los golpeaban en los canales patagónicos y fueguinos.

En este sentido, Jones agrega que la especulación y el riesgo caracterizaron a este rubro, en particular a partir de 1820, estimulando a muchos que sin previa experiencia en el negocio incursionaron en los mares del sur, adquiriendo embarcaciones de baja calidad con el fin de aminorar los riesgos de pérdida de la inversión. De igual modo, el riesgo estaba presente antes, durante y a regreso del crucero cinegético, en primer lugar, por la incertidumbre de dar con apostaderos de otáridos que permitieran rentabilizar la inversión, en segundo lugar, por las tormentas inesperadas, la niebla, los icebergs, etc., siempre estaba latente la posibilidad de pérdida total e incluso de no retorno de las tripulaciones, y en tercer lugar, porque existía incertidumbre en cuanto al precio de las pieles al volver a Inglaterra (1981, pp. 256, 260). En la última expedición llevada a cabo por William Low en 1832-1833, a bordo de la goleta Unicorn, realizada en asociación con otros inversores, seguramente para compartir los riesgos en caso de algo no saliera de acuerdo a lo planeado, los resultados fueron paupérrimos, dejando sin capital a Low, con su embarcación gravemente dañada, viéndose obligado a vender la goleta. A partir de allí, como se verá más adelante, utilizó buques menores, primero en las islas Falkland y posteriormente, en los canales al sur de la isla de Chiloé. Esta última situación sugiere, que sólo unos pocos marineros dedicados a la caza de lobos marinos pudieron hacer fortuna, sobre todo aquellos que llevaron a cabo sus actividades en los inicios de la actividad hacia fines del siglo XVIII y principios del XIX y tras los primeros años que sucedieron al descubrimiento de las Shetland del Sur cuando la abundancia de presas hicieron los viajes altamente rentables, como los de los norteamericanos Edmund Fanning, Ebenezer Townsend y Nathaniel Palmer. En el caso de los británicos y, siguiendo a Jones, la situación fue opuesta, ya que marinos devenidos en loberos y ligados a la exploración antártica, como William Smith, James Weddell y Edward Bransfield, terminaron sus días sumidos en la pobreza (1981, p. 260).

Más atrás, se informaba del encuentro de William Low con su hermano, quien venía de un viaje desde las Shetland del Sur a inicios de 1828, en procura de grasa de elefantes marinos. Este último antecedente, muestra que los Low realizaban operaciones combinadas de pesca de lobos y de elefantes marinos, las que como ya se dijo, eran llevadas a cabo en lugares remotos, tales como la isla Noir o las Shetland del Sur. Esta situación se encuentra relacionada con la disminución de las 
poblaciones de otáridos experimentada tras la gran afluencia de cazadores que afluyeron hacia latitudes australes a contar de 1819 , que trajo como consecuencia que los loberos que los sucedieron, tuvieran que recorrer una mayor amplitud de costa en procura de sus presas, de manera que los viajes redituaran lo que se esperaba de ellos. Se ha detectado esta misma modalidad en loberos norteamericanos, los que además de cazar lobos y elefantes de mar, simultáneamente cazaban nutrias, coipos y en algunos casos, agregaban a sus bodegas aceite de cetáceos $^{27}$, todos en época posterior a 1820, lo que evidencia la escasez de otáridos, obligándolos a ocuparse en la caza de otros mamíferos marinos. En consonancia con lo anterior, Watson (1931) señala que hacia fines de la década de 1830 se evidenció una fuerte disminución en la cantidad de otáridos y una fuerte baja en los precios de las pieles, forzando a las expediciones loberas estadounidenses, las que fundamentalmente partían de los puertos de New London, Stonington y Mystic, a volcarse a la extracción de aceite de elefantes marinos, faena que se mantuvo con buenos rendimientos hasta principios de 1870 (p. 477-478). De igual modo, valga mencionar que desde un principio la actividad lobera estuvo ligada o fue subsidiaria de la caza de cetáceos, de modo tal que los primeros balleneros que extendieron sus actividades desde el hemisferio norte a latitudes más australes, alrededor de 1774 y 1776, al percatarse de la abundancia de pinnípedos, concibieron la idea de obtener aceite no sólo de las ballenas, sino que también de lobos y elefantes marinos (Dickinson, 2007, pp. 25-26).

\section{El escenario geográfico y humano}

de acuerdo a los testimonios del lobero

Se ha establecido que William Low comenzó

27 A modo de ejemplo, se citan los siguientes casos que efectuaron específicamente sus actividades cinegéticas en Patagonia (occidental y oriental), Tierra del Fuego e islas Falkland: Goleta Harriet, que entre 1828-1830, se dedicó a la caza de lobos de dos pelos, lobos comunes, elefantes marinos y nutrias; bergantín Athenian, capitán Rowland Hallett, entre 1836-1839, caza lobos finos y comunes, además de nutrias, ballenas y cachalotes; goleta Betsey, capitán Noyes, entre 1840-1842, se dedica a la caza de lobos de dos pelos, lobos comunes, coipos y nutrias. Respectivamente, Log 107, Log 4 y Log 7, G. W. Blunt White Library, Mystic Seaport Museum, Inc. su deambular por el extremo austral sudamericano, por lo menos desde el año 1822, aún cuando esto pudo haber ocurrido desde 1813. Considerando esta última información y hasta llegar a 1841, año en que se reporta la muerte de este marino escocés en la isla de Chiloé, entera prácticamente tres décadas de recorridos por los intrincados vericuetos de la geografía patagónica y del archipiélago de las Falkland, lo que permitió que este singular personaje acumulara una valiosa cantidad de conocimientos respecto del medio geográfico y humano, gran parte del cual ha sido prácticamente desconocido y por ello escasamente valorado, -lo que igualmente se verifica para el caso de otros loberos-, lo que justifica abundar sobre el punto.

Charles Darwin, biólogo y naturalista que formara parte de la expedición comandada por Robert Roy, incluye en su diario de viaje, una vívida descripción del lobero William Low, justo en el momento en que este retorna de su desastroso crucero lobero con la Unicorn, en marzo de 1833 :

On Friday a sealing vessel arrived commanded by Capt. Lowe; a notorious \& singular man, who has frequented these seas for many years \& been the terror to all small vessels. - It is commonly said, that a Sealer, Slaver \& Pirate are all of a trade; they all certainly require bold energetic men; amongst Sealers there are frequently engagements for the best "rookerys". In these affrays Capt Lowe has gained his celebrity. - In their manners habits I should think these men strikingly resembled the old Buccaneers ${ }^{28}$ (Darwin, 2001, p. 148).

Según se aprecia, William Low gozaba de una fama de hombre rudo y dispuesto a todo con tal de proteger los mejores cotos de caza ante la

28 El viernes arribó un barco lobero comandado por el Capitán Lowe; un hombre notable y singular, que ha frecuentado estos mares durante muchos años y fue el terror a todos los barcos pequeños. Es común decir, que un lobero, un esclavista y un pirata son del mismo gremio; todos ellos ciertamente, requieren hombres enérgicos y audaces; entre los loberos, hay con frecuencia disputas por los mejores roqueríos. En estas reyertas, es donde el Capitán Lowe ha ganado su fama. En sus costumbres habituales, debo pensar que estos hombres se parecían notablemente a los antiguos bucaneros. 


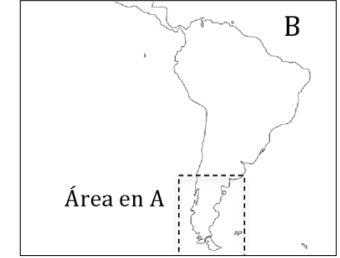

Fig. 3. A y B) Localización general área estudio. 1 Ancud, 2 canal de Chacao, 3 isla Huafo, 4 isla Gran Guayteca, 5 puerto Low, 6 archipiélago de los Chonos, 7 isla de las Cabras (Inchemó), 8 cabo Tres Montes, 9 fiordo Eyre, 10 isla Wellington, 11 canal Messier, 12 isla Madre de Dios, 13 golfo Trinidad, 14 canal Smith, 15 cabo Victoria, 16 canal Fitz Roy, 17 bahía San Gregorio, 18 punta Low, 19 península de Brunswick, 20 puerto del Hambre, 21 puerto San Antonio (isla Dawson), 22 bahía Bougainville, 23 isla Noir, 24 canal Bárbara, 25 península de Brecknock, 26 canal Magdalena, 27 canal Cockburn

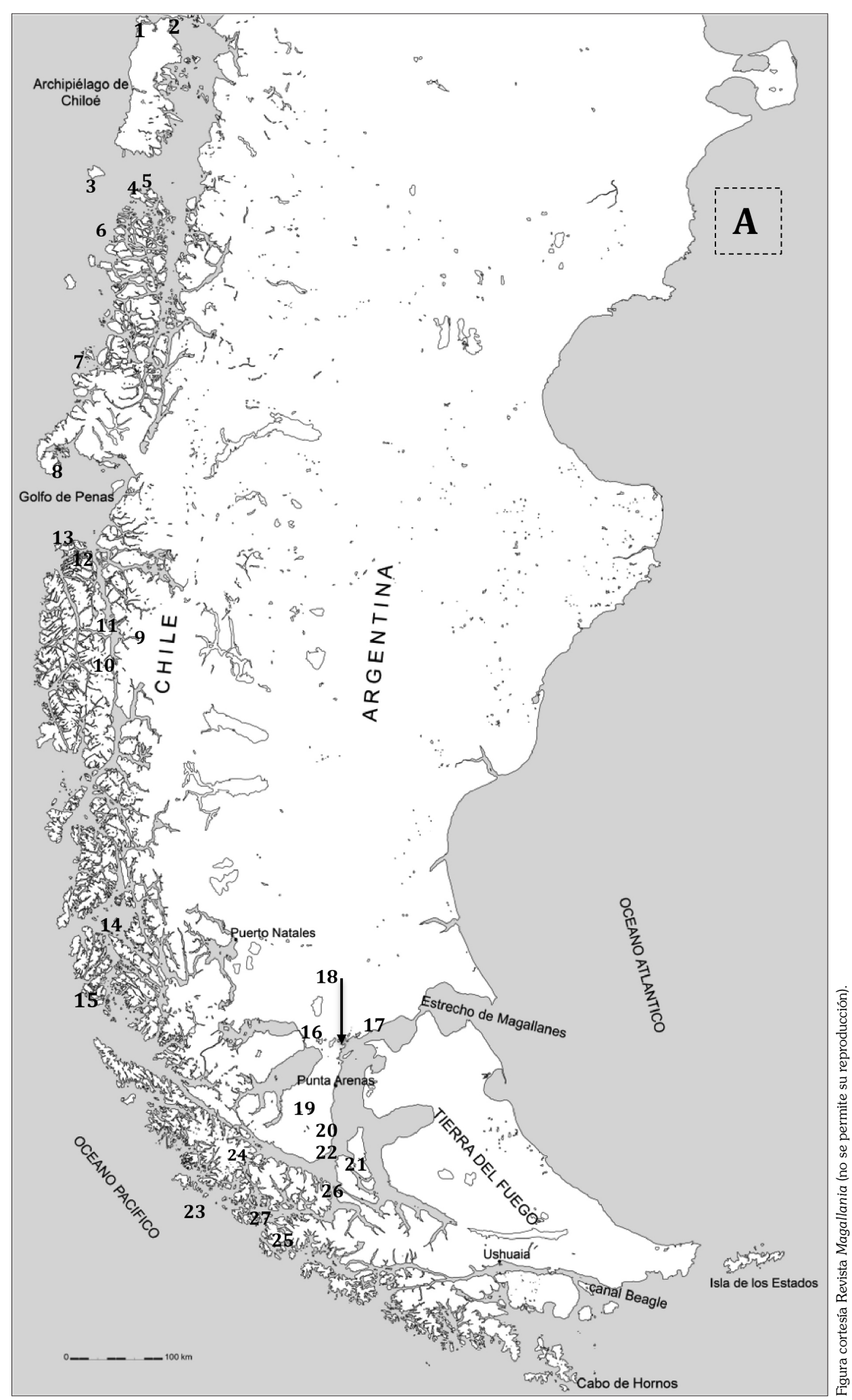


presencia de extraños, situación por lo demás común, sobre todo entre loberos norteamericanos y británicos, cuya rivalidad se veía acentuada por situaciones históricas recientes, particularmente tras la guerra de 1812 que enfrentó a las antiguas colonias americanas con su metrópoli. Darwin igualmente alude a la dilatada experiencia de este lobero, lo que se condice con lo que al respecto agrega Fitz Roy, cuando informa que Low es considerado el más emprendedor e inteligente lobero de los mares australes y quizás de todo el mundo, además de estimar que en cuanto a pilotaje $e$ información general sobre las islas Falkland, Tierra del Fuego, Patagonia e islas Galápagos, no había otro individuo con tal experticia (1839a, pp. 273, 331).

En lo que respecta al conocimiento geográfico, Low lo demostró en parte, cuando en mayo de 1830 , piloteó al Dryad, barco de la Compañía de la Bahía de Hudson (que iba con destino al río Columbia, costa nor-oeste de Estados Unidos) a través del canal Magdalena ${ }^{29}$, paso marítimo que permite la comunicación desde aguas interiores del estrecho de Magallanes hacia aguas abiertas del océano Pacífico. Junto con el canal Cockburn, mencionado en párrafos anteriores, constituyeron una vía marítima ampliamente utilizada por los loberos en su constante deambular en busca de presas, y según refiere Fitz Roy, Low habría sido el primero en recorrerlo en una embarcación mayor (1839a, p. 358). Estando en islas Falkland el Dryad tuvo la oportunidad se hacer el trato con el capitán del Adeona, quien arribaría el 3 de mayo para llevara cabo lo acordado (Parker King, 1839, p. 321).

El área archipielágica occidental de Patagonia fue también recorrida azmpliamente por Low, y tanto Fitz Roy como Darwin mencionan que mientras el lobero escocés se hallaba en las cercanías del golfo Trinidad (al sur de la isla Wellington), ofreció papas a los

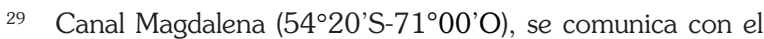
estrecho de Magallanes al oeste de la isla Dawson y corre en dirección norte-sur, para posteriormente, comunicarse

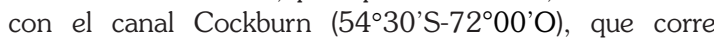
en dirección este-oeste, y que finalmente conecta con el océano Pacífico.

30 Los Veliche (Huilliche) denominaban a la papa silvestre malla o aquina, en contraposición a la poñi o papa sembrada. aborígenes del área, presumiblemente chonos, ya que al verlas refirieron la palabra aquina, que es la denominación dada por los indígenas del sur de Chiloé (Fitz Roy, 1839a, p. 200; Darwin, 1839 , p. 348 $)^{30}$. De igual modo, se registra su presencia en la isla Madre de Dios

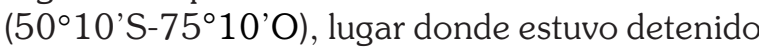
por tres semanas por causa del mal tiempo, oportunidad que aprovechó para recorrer el costado occidental de la isla en compañía de dos hombres de la etnia chono, con los cuales capturó algunos lobos marinos, los que posteriormente sirvieron de alimento para los nativos y donde pudo presenciar una ceremonia que estos llevaron a cabo antes de consumirlos. En otra oportunidad, navegando al sur de la citada isla, halló una caverna situada en una pequeña isla donde los aborígenes depositaban a sus muertos. (Fitz Roy, 1839a, p. 190-191) Los misioneros protestantes norteamericanos Titus Coan y Williams Arms, quienes entre noviembre de 1833 y marzo de 1834 estuvieron en la costa nororiental del estrecho de Magallanes con el objeto de evangelizar a los aborígenes aónikenk, son también una valiosa fuente de información. Mientras describen las características del área en torno a la bahía San Gregorio, refieren que a unos setenta u ochenta kilómetros al interior, el capitán lobero William Low plantó papas allí, las que alcanzaron un buen tamaño y tenían un excelente sabor. También plantó verduras y frutas pero no pudo verificar si han germinado o no (Coan, 2006, p. 193). Lo anterior, da cuenta de una presencia constante por parte de Low, no sólo por los intrincados canales patagónicos en el marco de sus actividades cinegéticas, sino que también de largas excursiones al interior del territorio, seguramente con el fin de proveerse de elementos básicos como agua y leña y de producir otro tipo de vegetales que de manera natural no se hallaban en la zona, de forma tal de contar con suministros frescos luego de tan largos

(Cárdenas, Grace y Montiel, 1991, p. 165).

31 En el año 2000, la arqueóloga Dominique Legoupil realizó un hallazgo de restos humanos con una data superior a 4000 años de antigüedad en la cueva de Ayayema, isla Madre de Dios (Legoupil y Sellier, 2004). Adicionalmente, en el año 2006, un equipo de espeleólogos franco-chilenos descubrieron pinturas rupestres en una caverna situada en la mencionada isla (Sepúlveda, 2011, p. 198). 
viajes. Existe el antecedente de la intención por parte de este lobero británico de construir una casa en la bahía de San Gregorio y traer consigo a otras personas para instalarse allí, proyecto que expuso a la india María, una destacada mujer que formaba parte de una de las principales parcialidades aónikenk hacia mediados del siglo XIX (Fitz Roy, 1839a, p. 169).

Más adelante agregan los misioneros que el nombre del capitán Low es respetado por todos y muchos exhiben lo que él les ha regalado ( $p$. 212). Señalan también, que en enero de 1834 , se encuentran con un joven desertor de la goleta norteamericana Transport, embarcación que a inicios de 1833 había naufragado al suroeste de la Tierra del Fuego y cuya tripulación fue auxiliada por el Unicorn del capitán Low, quien finalmente los condujo hasta las islas Falkland, no sin antes, a petición del propio muchacho de nombre Nicholas Druery, detenerse en bahía San Gregorio para desembarcar y continuar su vida entre los Aónikenk (p. 100). Cabe destacar que la versión del naufragio que proporciona el joven norteamericano Druery, se confirma con la información aportada al respecto por Fitz Roy, cuando este se encuentra con Low en las islas Falkland en marzo de 1833.

El archipiélago de las Falkland fue otro de los lugares de habitual recorrido por parte del capitán Low, lugar donde acudió con frecuencia desde 1822 hasta 1834, cuando abandona estas islas para posteriormente radicarse en la isla de Chiloé. Este grupo de islas del Atlántico sur eran la primera parada de los loberos luego de atravesar dicho océano, donde podían reabastecerse de agua, vegetales y carne, este último recurso muy abundante, no sólo por la gran cantidad de aves presentes en las islas, sino que también, debido a la numerosa presencia de bovinos y porcinos, especies que fueron introducidas por colonos franceses a contar de 1764. Charles Darwin comentaba en marzo de 1834 sobre las características de una especie endémica del archipiélago, el zorro-lobo malvinero (Dusicyon australis), y al particular refería que el capitán Low, persona inteligente y que estando largamente familiarizado con estas islas, sostenía que dichos cánidos presentaban diferencias en tamaño y color según se tratasen de los que habitaban West Falkland o East Falkland
(Darwin, 1839, p. 250). Su conocimiento del área se aprecia también, durante los casi cuatro meses que exploró las costas exteriores del sur y oeste del archipiélago, esta vez empleado como piloto a bordo de la goleta Adventure (ex Unicorn), lugares de los que conocía cada puerto y sus peligros (Fitz Roya, 1839, p. 332).

Para una permanencia tan prolongada en el tiempo recorriendo las aguas, litorales y tierras interiores de las áreas que se han venido señalando, Low hubo de contar con el conocimiento aportado por la experiencia, lo que sin embargo no sería suficiente, ya que este singular personaje debió comprender tempranamente que para poder sobrevivir en estas latitudes, era necesario establecer buenas relaciones con los nativos del lugar, de quienes mediante el trueque se podían obtener alimentos guanaco y huevos, así como también pieles y plumas. Estos intercambios materiales resultaron ser habituales entre loberos y aborígenes, tanto por necesidad y conveniencia recíproca, aunque también se dieron intercambios simbólicos, donde el lobero escocés pudo conocer información de primera fuente respecto de las costumbres y conocimiento ancestral que de su territorio poseían los aborígenes con quienes interactuó.

De ahí que se comprenda el hecho de que gran parte de la información referida a los aborígenes que pudieron recoger los marineros británicos en la antes aludida expedición llevada a cabo entre 1826 y 1834, fueran tomadas de William Low, a tal punto que según afirma Fitz Roy, determinados pasajes de su relato fueron escritos directamente según el dictado del sealer británico (1839a, p. 169).

En particular, entrega abundante información respecto de parcialidades aónikenk (cazadores-recolectores terrestres), kawésqar y chono (cazadores-recolectores marinos), lo que es coherente si se consideran las singladuras de Low a lo largo de los años, que se concentraron en el estrecho de Magallanes y la costa occidental de Patagonia, hasta la latitud de la isla de Chiloé, lugares que constituían el hábitat desde tiempos pretéritos para dichas culturas.

Por razón de la cantidad de antecedentes al respecto, únicamente se entregarán algunos pormenores de la interacción entre los aborígenes y este cazador de lobos marinos, específicamente 
aquellos que dan cuenta de intercambios simbólicos y materiales. En tal sentido, resulta notable el conocimiento que manifestó Low respecto de las distintas parcialidades aónikenk que habitaban a lo largo e interior de la costa nororiental del estrecho de Magallanes, en particular de un grupo mestizo denominado despectivamente como zapallos:

Mr. Low said, that the tribe on the banks of this channel were mixed, being partly horse and partly canoe Indians. They were entirely under the dominion of the Gregory Bay party, who appointed their chiefs. Maria's son, called 'Capitan Chico,' was their ruler, until the arrival of Capitan Chups (Fitz Roy, 1839a, p. 170) ${ }^{32}$.

En la cita precedente, se hace referencia a un encuentro llevado a cabo a inicios de 1833 en la costa del canal Fitz Roy ${ }^{33}$, cuando la goleta Unicorn aún pertenecía al capitán Low, lugar donde arribaron un grupo de aónikenk y el aludido grupo mestizo, parte de cuyos integrantes eran vendidos como esclavos a los primeros, información que el lobero obtuvo de boca de la ya aludida india María:

A part though of that amicable intercourse consists in selling their children to the Patagonians for slaves. The following incident led to the discovery of this slavetrade: Mr. Low heard Maria talking of 'zapallos,' and asked her if she could get some for him-and how many? He thought she meant pumpkins (for which zapallos is Spanish); Maria replied, 'two boat loads', and to show of what, pointed to a young slave, lately purchased from the Fuegians (Fitz Roy, 1839a, p. 171) ${ }^{34}$.

32 Mr. Low señalaba que la tribu de esta orilla del canal era mezclada, siendo en parte indios de a caballo y de canoa. Estaban completamente bajo el de dominio del grupo de había Gregorio, la que nombraba a sus jefes. El hijo de María, llamado 'Capitán Chico', era su jefe hasta la llegada del 'Capitán Chups'.

33 Canal Fitz Roy (52 $45^{\prime}$ S- $71^{\circ} 25^{\prime}$ O) se encuentra localizado al oeste de la península de Brunswick, y une las aguas de los mares de Otway y Skyring.

34 No obstante, una parte de estas relaciones amistosas consiste en vender a sus hijos como esclavos a
Dicha información entregada por Low, es una de las primeras y escasas referencias de esta mezcla interétnica entre aónikenk y kawésqar, grupo que en años posteriores, tras la fundación del Fuerte Bulnes en 1843, serían mejor conocidos como guaicurúes (Martinic, 1995, p. $89)^{35}$. A partir del mencionado encuentro, Fitz Roy menciona al pasar que a bordo del Unicorn se hallaba un joven patagón (aónikenk) que llevaba cuatro meses con el capitán Low y que lo había acompañado a Montevideo (p. 170). Tal información que coincide con la antes aportada respecto del último viaje que este realizó hacia dicho puerto al mando del bergantín Adeona, lugar donde la embarcación es dada de baja y en el mes de septiembre de 1832 adquiere la goleta Unicorn. Como se verá más adelante, la presencia de aborígenes a bordo de una embarcación de Low, no constituía un hecho aislado, y en este caso particular, el joven patagón debió ser reclutado como intérprete entre los indios de la costa nororiente del estrecho de Magallanes, ya que según relata Fitz Roy, el muchacho le ayudó al lobero a comprarles pieles a un grupo de aborígenes kawésqar que se hallaban en la isla Isabel y más tarde, tras ser dejado junto a su familia en la bahía de San Gregorio, se dio al trabajo de recopilar pieles únicamente para su amigo el capitán Low (p. 173).

En este último punto, se deja entrever una modalidad de trato mercantil entre aborígenes y loberos, consistente en encargar a los primeros el acopio de pieles de lobos marinos, mientras los loberos efectuaban sus actividades de caza en otros lugares, tiempo después del cual regresaban a recoger las pieles recolectadas por los naturales y que les eran recompensadas por medio del trueque. Esta modalidad ha sido observada en expediciones loberas yankees,

los patagones. El siguiente incidente llevó al descubrimiento de este comercio de esclavos: Mr. Low escuchó a María hablar de 'zapallos', y le consulto si podía conseguirle algunos y cuántos?. Pensó que ella quería decir calabazas (que en español se llaman zapallos); María le contestó, 'dos botes cargados', y para mostrarle de qué, apuntó a un joven esclavo, recientemente comprado a los fueguinos.

35 Para más información respecto de este grupo aborigen, véase Martinic (2007). 
quienes por ejemplo, además de trocar pieles, obtenían de los chonos al sur de Chiloé, papas $y$ otros vegetales y carne de guanaco de los aónikenk en el estrecho de Magallanes ${ }^{36}$.

En efecto, a bordo del Adeona estuvieron 18 y 14 meses respectivamente, dos aborígenes chono, Bob y Niqueaccas. El primero fue embarcado tras una disputa entre Low y los miembros de la parcialidad a la que pertenecía Bob, producto del hurto de algunas especies mientras se encontraban a bordo del bergantín. Tras esto, el muchacho de 10 años, las ofició de práctico y fue llevado en uno de los viajes del lobero escocés hasta las islas Galápagos, lugar donde de acuerdo a Fitz Roy, el muchacho hizo gala de su conocimiento de los canales patagónicos, dibujando en la cubierta de la embarcación lo que parecía ser una carta de lo que el capitán Low supuso era el fiordo Eyre ${ }^{37}$. Posteriormente Bob fue dejado en la bahía de San Gregorio junto a un grupo de aónikenk, quienes lo habrían recibido como si fuera un hijo de Mr. Low, a pesar de que en el pasado, jamás había estado al sur del estrecho de Magallanes. Niqueaccas fue embarcado en calidad de práctico en las cercanías del cabo Victoria ${ }^{38}$ y demostró ser un avezado conocedor de las costas desde el estrecho de Magallanes hasta el paralelo $47^{\circ}$, de modo tal que le proporcionó a Low la ubicación de los mejores puertos y loberías de la zona, para lo cual solamente le bastaba a Niqueaccas, con ascender a un cerro y desde ahí indicar la posición del lugar más adecuado. Al igual que Bob, durante el tiempo que permanecieron a bordo del barco lobero, aprendieron el idioma inglés. (pp.189,192,194, 221, 222).

Dada la escasez de datos que hablen de la

36 A los ya citados logbooks del Betsey (Log 7) y Athenian (Log 4), se consignan intercambios efectuados por la goleta Betsey al sur de Chiloé y en el estrecho de Magallanes, Logbook of the Betsey (OLog 6), G. W. Blunt White Library, Mystic Seaport Museum, Inc.

37 Fiordo Eyre (49 $\left.20^{\prime} \mathrm{S}-74^{\circ} 00^{\prime} \mathrm{O}\right)$, se ubica al oeste de la isla Wellington $\left(49^{\circ} 00^{\prime} \mathrm{S}-74^{\circ} 45^{\prime} \mathrm{O}\right)$.

38 Cabo Victoria (52 $\left.17^{\prime} \mathrm{S}-7^{\circ} 56^{\prime} \mathrm{O}\right)$, se localiza en la boca occidental del estrecho de Magallanes.

39 En el Apéndice del Tomo II de la publicación editada por Fitz Roy y publicada en 1839 (Fitz Roy, 1839b, p. 142), se incluye un breve capítulo conteniendo un vocabulario de palabras kawésqar, yámana, aónikenk y chono. Respecto de éstos últimos, únicamente incluye tres vocablos, que corresponden a los nombres de las deidades aludidas en la religiosidad de los chono, se cree necesario incluir algunos testimonios que dan luces la espiritualidad de este pueblo. Fitz Roy basado en gran parte en los datos del lobero escocés, incluye una referencia prácticamente desconocida, atingente a las ideas mítico-religiosas y cosmogonía de este pueblo canoero $^{39}$ :

The people of this tribe* are by no means without ideas of a superior Being. They have great faith in a good spirit, whom they call Yerri Yuppon, and consider to be the author of all good: him they invoke in time of distress or danger. They also believe in an evil spirit, called Yaccy-ma, who they think is able to do all kinds of mischief, cause bad weather, famine, illness, \& c.: he is supposed to be like an immense black man. ("chono) (...)

The natives of this tribe* suppose that all white people originally came from the moon; they call them "cubba;" and often make use of an expression with reference to them which means 'White men of the Moon'. ("chono) (Fitz Roy, 1839 a, p. 190$)^{40}$.

En el mismo sentido, en párrafos anteriores, se aludía a la permanencia de William Low entre una parcialidad de los chono, donde pudo presenciar una ceremonia llevada a cabo por éstos, toda vez que logran conseguir alimentos tras un periodo prolongado de escasez, así como también, observar una caverna con restos humanos. Este ritual se realizaba entre todos los miembros de la tribu, quienes se disponían alrededor de una

cita.

40 La gente de esta tribu (chono) no carece de ideas de un Ser Superior. Tienen gran fe en un espíritu bueno que ellos denominan Yerri Yuppon y lo consideran el autor de todo lo bueno; lo invocan en época de padecimientos y peligro. También creen en un espíritu maligno, llamado Yaccy-ma, de quien suponen es capaz de hacer todo tipo de maldades, causando mal tiempo, hambre, enfermedades, etc.: lo imaginan como un inmenso hombre negro.

La gente de esta tribu (chono), supone que toda la gente blanca proviene originalmente de la luna; los llaman 'cubba'; a menudo hacen uso de una expresión con referencia a aquellos que significa 'hombres blancos de la luna". 
fogata, esperando bajo un absoluto orden que el más anciano les entregase a cada uno su porción respectiva, lo que iba acompañado de una suerte de oración que el anciano reiteraba rápidamente mirando hacia el cielo. Toda vez que cada miembro de la tribu tuvo en sus manos su porción, procedieron a tocar el alimento, en este caso un lobo marino, del cual Low igualmente recibió una porción, según le refirió al marino británico. En cuanto al sitio funerario hallado por Low al interior de una pequeña caverna, refiere que su interior estaba repleto de osamentas humanas y pudo ver el cuerpo de un niño, que estaba en estado de descomposición. Los cuerpos se encontraban dispuestos en tumbas poco profundas alrededor de la caverna y estaban cubiertos por hojas y ramas. (Fitz Roy, 1839a, pp. 190-191).

Diferenciando el carácter de los chonos con respecto al de los kawésqar, Low proporciona el siguiente relato:

One day several of these people had gone on board the Adeona with some old axes and pieces of iron, which they wished to have ground at her grindstone (a favour which had often been granted); but in consequence of something having gone wrong in the vessel, which had ruffled Low's temper, he rather roughly refused to let them stay on board. They went away quietly, but left their axes, \&c. behind; and while returning were met by the mate of the vessel, who asked if they had ground them; they replied negatively, and gave the mate to understand that the captain's face was too long, but that they would come again when it was shorter.

41 Un día, varias de estas personas [grupo chono] habian ido a bordo del Adeona con algunas hachas viejas y pedazos de hierro, las que deseaban afilar en la piedra (favor que se les realizaba a menudo); pero debido a algo que había andado mal en la embarcación, y que había alterado el ánimo de Mr. Low, este rechazo que se quedasen a bordo. Se marcharon tranquilamente, pero dejaron sus hachas, etc.; y mientras regresaban se reunieron con el segundo oficial del barco, quien les preguntó si habían podido afilar; respondieron negativamente, y dieron a entender al segundo oficial que la cara del capitán estaba muy larga, pero regresarían en tanto se le vuelva a acortar. Esto ocurrió antes de que Niqueaccas y el niño fueran
This occurred before either Niqueaccas or the boy had been taken on board the Adeona.

Mr. Low remarked to me that the conduct of these Indians on this occasion of his harshly refusing to comply with a slight request, was quite different from that which the Fuegians would have shown under similar circumstances: they would have been angry, and in all probability have returned his ill-temper with a display of their own, evinced by a shower of stones (Fitz Roy, 1839a, p. 196) ${ }^{41}$.

Tanto el fiordo Eyre como el cabo Victoria, son accidentes geográficos situados en el territorio que históricamente formó parte del hábitat de los kawésqar, por lo que no deja de llamar la atención que aborígenes chono, hayan incursionando tan al sur de su territorio histórico. Siguiendo a Cárdenas et al. (1991), el territorio chono abarcaba desde el norte del estuario de Reloncaví y canal de Chacao, hasta el golfo de Penas por el sur, sin embargo, con la llegada de los europeos, dicha área se hubo de modificar, sobre todo tras la presencia y actividad misional de los jesuitas a contar del siglo XVII, quienes trasladaron a gran cantidad de contingente chono a la isla de Caylin (en Chiloé). Un grupo de chono pudo escapar refugiándose más al sur hasta el archipiélago Wellington, lugar ocupado por la etnia kawésqar (p. 99) ${ }^{42}$. Tal situación explicaría la presencia de chonos más al sur del golfo de Penas, situación que ya suponía en su momento Fitz Roy, al comentar que éstos, producto de su esporádico trato con los españoles al sur de Chiloé, eran de mejor trato que sus vecinos kawésqar y que tras la conquista

tomados a bordo del Adeona.

Mr. Low me recalcó que la conducta de estos indios en ocasión de su duro rechazo a cumplir con su ligera petición, era bastante diferente de la que se hubiese observado en los fueguinos en similares circunstancias: éstos se habrían enojado, y con toda probabilidad habrian respondido a su mal humor [de Low] con su propia demostración, expresado en una lluvia de piedras" [Lo agregado entre corchetes es nuestro].

42 Complementariamente, hacia fines del siglo XIX, Thomas Bridges daba cuenta de la presencia de aborígenes chonos cerca de la isla Wellington (Bridges, 2000, p. 127, citado en Álvarez, 2002, p. 81). 
española, muchos de ellos se encontraban al sur del cabo Tres Montes (Fitz Roy, 1839a, p. 142). Y si cabe alguna duda, el oficial del almirantazgo proporciona una serie de descripciones físicas de estos aborígenes canoeros y respecto de sus embarcaciones, la dalca, las cuales reafirman la filiación etnográfica que se viene señalando. Estas informaciones en complemento con las entregadas por Low, son una valiosa fuente de referencias respecto del pueblo chono, aborígenes canoeros cuya población se vio diezmada tempranamente tras el contacto con foráneos, y ya para fines del siglo XVIII, se encontraban prácticamente extintos.

La información aportada por Low a los hidrógrafos británicos, denota una prolongada presencia en el distrito patagónico, donde la interacción llevada a cabo con los aborígenes no sólo se llevó en términos amistosos, sino que también, en ocasiones ésta se manifestó en situaciones conflictivas, como se aprecia en el embarque del niño chono Bob a bordo del Adeona o el caso en que un holandés de la tripulación de Low fue laceado desde un bote por los aónikenk y obligado a permanecer en la costa. En esta misma línea, Parker King menciona una suerte de carta o memorándum dejada por el capitán William Low a María (quien formaba parte de una parcialidad aónikenk), donde informaba a todos quienes navegasen por el estrecho de Magallanes, de la amistosa disposición de los aborígenes, la necesidad de tratarlos bien y no engañarlos, debido a que por un lado tenían muy buena memoria, y por otro, podrían ofenderse seriamente (Parker King, 1839, p. 114). Esta carta más que propender a la protección de los nativos, da cuenta de un interés manifiesto en que los demás loberos u otros navegantes que se detuviesen en el estrecho magallánico, no actuarán en la dirección contraria, y de ese modo interfirieran en el provechoso intercambio desarrollado entre los aborígenes y loberos.

43 Matthew Brisbane, fue en lobero escocés que en el año 1822 acompañó al explorador antártico y lobero británico James Weddell. Posteriormente en el contexto de expediciones loberas, Brisbane naufraga en tres oportunidades, la primera en las costas del canal Cockburn (1826) y la tercera ocasión en la costa oriental de Tierra del Fuego (1830). Se radica en las islas Falkland, donde trabajaba para Luis Vernet, un comerciante de origen alemán, que recibió una

\section{Últimos años de Low en Chile}

Hasta aquí, se han entregado antecedentes atingentes a la caza de lobos marinos, a partir de la trayectoria del lobero escocés William Low, procurando extrapolar su quehacer en el contexto global de una actividad económica que por su envergadura sería la primera en desarrollarse en el territorio magallánico y que a la sazón, contribuiría a la incorporación en los circuitos mercantiles de vastos e inexplorados territorios. Lo anterior, a partir de una perspectiva de análisis microhistórico, basada en el estudio de las existencias individuales, con el fin de complementar la historia de las grandes transformaciones sociales, por cuanto la tarea del historiador, consiste en explorar las relaciones entre los distintos niveles (macro y micro) de la experiencia histórica (Iggers, 2012, p. 171).

En una vinculación con el contexto regional o local, la figura de Low se imbrica con la isla de Chiloé, cuando allí se radica a contar de 1834, dando paso algunos años después, al inicio de su estirpe en suelo chileno, de tan frecuente presencia en territorio chiloense y magallánico; igualmente, adquiere notoriedad cuando en el año 1842 comenzaron los preparativos para organizar una expedición desde aquella isla, con el objetivo de tomar posesión a nombre de la República de Chile del estrecho de Magallanes y territorios adyacentes, momento en el cual se pensó en su persona.

Más atrás se mencionaba la venta que hubo de realizar Low de su goleta Unicorn en marzo de 1833. Tras esto, decide quedarse en Port Louis (East Falkland), donde se alojó en casa de un viejo amigo y colega, el lobero escocés Matthew Brisbane $^{43}$, de largo recorrido por los mares australes. Entre marzo y agosto de 1833, Low seguiría dedicándose a la caza de lobos marinos, pero esta vez con un bote ballenero y una pequeña tripulación de cuatro hombres. Justamente, el día 23 de agosto de 1833, Low se dirigió a puerto Johnson (al noreste de Port Louis, a orillas del

concesión del gobierno de las Provincias Unidas del Río de la Plata en 1828 para generar un establecimiento en las Falkland y posteriormente se le otorgó autoridad política y militar sobre el archipiélago y la isla de los Estados. Brisbane es asesinado en agosto de 1833 en su casa en Port Louis, por un grupo de gauchos descontentos que trabajan a su cargo. 
fiordo Berkeley) en procura de otáridos, decisión que resultó ser providencial, ya que momentos después se produciría el asesinato de Matthew Brisbane y cuatro personas más, y de acuerdo al relato de Helsby ${ }^{44}$, Low estaba entre los objetivos de los asesinos. Tras informarse de los hechos, Low se retira a los islotes Kidney, situados a la entrada del fiordo Berkeley, lugar donde permanecerá hasta el 6 de febrero de 1834, cuando se encuentra con el teniente Wickham, ahora a cargo de la Adventure. A contar de la fecha señalada y hasta fines de mayo, Low las oficiaría de práctico a bordo de su otrora embarcación lobera y en tales circunstancias procedieron a realizar levantamientos hidrográficos en la costas exteriores del sur y oeste de las islas Falkland. A contar del 23 de mayo, siguieron su tarea exploratoria en las costas del estrecho de Magallanes, para finalmente anclar en la bahía de San Juan a inicios de junio.

Desde aquel lugar zarpan con destino a la isla de Chiloé, el 9 de junio, arribando a punta Arenas $^{45}$, en las cercanías de San Carlos de Ancud, a fines del mismo mes. Tras abastecerse de víveres y realizar algunas mantenciones a las embarcaciones, ambas se dirigen a Valparaíso ${ }^{46}$. Low se queda en Ancud, con la responsabilidad de llevar a cabo un viaje exploratorio en el archipiélago de los Chonos. Para tal efecto, Fitz Roy le asigna un bote ballenero, además de proveerle de dinero, una carta hidrográfica y algunos instrumentos náuticos. Low contrató una variopinta tripulación compuesta de 6 individuos: un galés, dos chilotes, un chileno y dos isleños de las Sandwich (archipiélago de Hawai). A excepción del galés, los demás trataron de que la expedición terminase antes de tiempo, para lo cual se concertaron para acabar con las provisiones $y$

44 Gran parte de los pormenores de este luctuoso hecho, fueron relatados por el inglés Thomas Helsby, quien se encontraba en el asentamiento al momento de suscitarse los asesinatos. Véase: Helsby (1968).

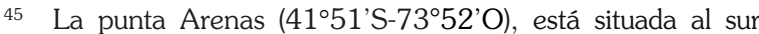
este de la península de Lacuy $\left(41^{\circ} 48^{\prime} \mathrm{S}-74^{\circ} 00^{\prime} \mathrm{O}\right)$, frente a la bahía de Ancud.

46 La Beagle y Adventure partieron a Valparaíso el día 14 de julio de 1834, con el fin de dirigirse a Santiago, para requerir la autorización del gobierno de Chile, para seguir con el levantamiento de las costas de su jurisdicción. En su permanencia en Valparaíso, donde arribaron el 23 de julio, Fitz Roy se entera que sus superiores desde Inglaterra, habian desautorizado la compra de la antes "Unicorn", ante lo cual, debió desprenderse de aquella goleta, que había de esta forma forzar el regreso. Sin embargo, y de acuerdo a lo que señala Fitz Roy:

Low was too much inured to hardship to be so easily diverted from his plan; he went on, directly south, even after his provisions were consumed; obliging them to live for fourteen days upon shellfish and sea-weed. After exploring much of the Chonos Archipelago, sufficiently to facilitate our survey materially, he returned with his hungry crew to Caylin ${ }^{47}$ (p. 364).

Tal como Darwin describiera en su momento el carácter de Low, en este caso Fitz Roy complementa lo señalado por el naturalista, en cuanto a que el experimentado hombre de mar poseía gran determinación y arrojo, máxime si se trataba de lidiar con tripulaciones descontentas, como quedaría demostrado en otra oportunidad cuando Low dejó a dos portugueses en bahía Peckett ${ }^{48}$, los que fueron hallados por la goleta auxiliar de la expedición comandada por Philip Parker King en agosto de 1828, quienes se hallaban junto a una parcialidad aónikenk de la india María (Parker King, 1839, pp. 183-184). El liderazgo era una cualidad fundamental que debían poseer los capitanes loberos, debido a que por la naturaleza de la actividad, caracterizada por hacinamiento, falta de provisiones, precariedad, peligros y riesgos de motines, dicho atributo era requisito sine qua non, a lo que se debe agregar, como bien señala Jones, que a bordo de estas embarcaciones no regían las leyes de la disciplina naval (1981, p. 261).

La Beagle regresa a San Carlos de Ancud

sido solventada con sus propios recursos. De acuerdo al hidrógrafo británico, la embarcación fue vendida en $£ 1400$ (la había adquirido por $£ 1300$ a Low) y hacia el año 1838 se encontraba ocupada en el tráfico de las costas chilenas (Fitz Roy, 1839a, pp. 440-441).

47 Low esta demasiado acostumbrado a las dificultades como para ser tan fácilmente desviado de su plan; prosiguió directamente al sur, obligándoles por catorce días a vivir en base a marisco y algas. Después de explorar gran parte del archipiélago de los Chonos, lo suficiente para facilitar materialmente nuestro levantamiento, regresó con su hambrienta tripulación a Caylin.

48 Bahía Peckett $\left(52^{\circ} 45^{\prime}\right.$ S- $\left.70^{\circ} 45^{\prime} \mathrm{O}\right)$, se localiza en la costa nororiental del estrecho de Magallanes. 
el 21 de noviembre de 1834 proveniente desde Valparaíso, oportunidad en la que Low pudo informarle de su actividad exploratoria. Por lo tanto, antes de volver a reunirse con los hidrógrafos británicos, Low permaneció en la isla de Chiloé por espacio de cuatro meses, teniendo en cuenta que sólo ocupó 14 días en llevar a cabo el recorrido encomendado, por lo que el resto del tiempo hubo de utilizarlo en establecer relaciones con gente de la isla, ya que cómo se indicó más atrás, por lo menos desde 1826 se registra allí su presencia.

Valga mencionar, que casi coetáneamente se encontraban en Chiloé otros tres británicos, John Williams y John Yates, en Ancud, en tanto que en Curaco de Vélez ${ }^{49}$, se hallaba radicado Carlos Miller, estos últimos dedicados a la caza de lobos marinos, en tanto que Williams, ejercía como funcionario de la Armada Nacional como capitán de puerto de Ancud (Braun, 1968, pp. 96, 119, 125). Estos tres hombres, quedarán vinculados entre sí, ya que todos estarían en la cubierta de la goleta Ancud en 1843, año en que se ejecutó la expedición de toma de posesión del estrecho magallánico.

Desde Ancud, Low se embarca nuevamente en calidad de práctico, esta vez a bordo de la Beagle, con destino al archipiélago de los Chonos, lugar donde junto a otros seis hombres se dedicaron a explorar el área norte de aquel grupo de islas, para finalmente reunirse el 7 de enero de 1835 con los demás miembros de la expedición en puerto Low, en la isla Gran Guayteca (ver Fig. 3). Once días más tarde arriban a punta Arenas, frente a Ancud, donde los hidrógrafos británicos permanecen hasta el 5 de febrero, para dirigirse a Valdivia a continuar con el levantamiento de las costas chilenas.

Hasta aquí llega el trabajo de Low como piloto de la ya citada expedición, razón por la cual se deduce que a contar de aquella fecha se radica definitivamente en Chiloé. Los antecedentes históricos hasta ahora conocidos, traen a la palestra nuevamente la figura del lobero escocés en los momentos en que se comienza a materializar el proyecto ideado por Bernardo O'Higgins, referidos a la toma de posesión del estrecho de Magallanes. Precisamente, por recomendación de O'Higgins,

49 Localidad situada en la parte noroeste de la isla de Quinchao

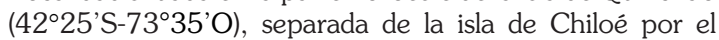
canal de Dalcahue.

50 Archivo Nacional Histórico de Chile, Fondo Ministerio de quien como es sabido, tras su abdicación se radicó en la hacienda de Montalván en Perú, llega a oídos del Presidente Manuel Bulnes y sus ministros, la idea de llevar a cabo el proyecto de ocupación y colonización del estrecho de Magallanes, además del nombre de quien podría comandar aquella expedición, aspectos que son recogidos por el ministro del interior Ramón Luis Yrarrázaval en la siguiente comunicación fechada en 30 de septiembre de 1842:

\section{El Sr Capitán Jeneral Don} Bernardo O'Higgins, habiendo concebido y comunicado al Gobierno el grandioso proyecto del establecimiento de una colonia en el Estrecho de Magallanes $y$ de vapores para remolcar los buques que vienen al Pacífico, ha indicado últimamente al Gobierno lo conveniente que sería colocar en la marina chilena al capitán Lowe, que sirvió en clase de piloto con el célebre marino Fitzroy, el cual posee conocimientos especiales de aquel Estrecho y de la Tierra del Fuego, y en concepto del Sor [sic] O'Higgins dicho capitán debe existir en el Archipiélago de Chiloé $(. . .)^{50}$.

La misión de organizar la expedición le fue encomendada a Domingo Espiñeira, quien sería nombrado Intendente de Chiloé a contar del 1 de abril de 1842. En una comunicación dirigida al Ministro de Marina de la época (Manuel Montt), Espiñeira da cuenta del destino final de William Low:

(...) Un hombre había en esta provincia, natural de Inglaterra, que empleó un buen tercio de su vida en viajes continuos desde este puerto a la península de los tres montes y de allí, hasta el interior del estrecho de Magallanes con el interés de la pesquería de lobos de dos pelos, gatos marinos y nútrias; pero por desgracia este hombre de quien se podía

Marina, Volumen 71, Informe Nro. 141 del Ministro del Interior, Ramón Luis Yrarrázaval, 30 de septiembre de 1842. 
haber sacado los informes más precisos en este particular, murió en septiembre del año anterior. Se llamaba Guillermo Low y el crédito que llegó a adquirir de perito en el conocimiento de toda esta costa hasta el cabo de hornos sirvió para que el capitán $D^{n}$ Robert Fitzroy de la marina de S.M.B. le escogiese de piloto práctico para su viaje científico de esploración: con dicho carácter acompañó Low al Sr Fitzroy en sus trabajos por las costas del sud de Chile y según estoy enterado hace de él una mención honrosa en la obra que no ha mucho ha publicado (... $)^{51}$.

No existen antecedentes que permitan conocer las circunstancias ni el lugar donde acaeció el deceso de William Low, salvo la escueta mención de Braun quien refiere que el lobero yace bajo el túmulo y la cruz de algún cementerio local (1968, p. 84). Conocido es que el proyecto de ocupación pudo concretarse el 21 de septiembre de 1843, cuando la goleta Ancud, capitaneada por el marino inglés John Williams, toca en las costas del paso interoceánico en la punta Santa Ana y proceden a tomar posesión a nombre de la República de Chile, del estrecho de Magallanes y territorios adyacentes. En este periplo tuvieron participación otros dos loberos británicos, Carlos Miller ${ }^{52}$, quien se incorporó a la tripulación de la goleta Ancud a los días de iniciada la travesía, en mayo de 1843, en tanto que John Yates ${ }^{53}$ participó del viaje el 5 de julio, con el fin de guiar a la goleta en el tramo que va desde puerto Americano a la isla de las Cabras ${ }^{54}$ (ver Fig. 3).

51 Archivo Nacional Histórico de Chile, Fondo Ministerio de Marina, Volumen 70, Informe Nro. 82 del Intendente de Chiloé, Domingo Espiñeira, al Ministro de Guerra Manuel Montt, 9 de mayo de 1842.

52 En relación a Carlos Miller, John Williams refiere que al llegar a la localidad de Curaco de Vélez encontró un segundo Low, un hombre que ha pasado tres inviernos $y$ veranos en los Estrechos, hombre formal y de inteligencia: he tenido a bien engancharlo en la plaza de marinero primero, dándole como a los otros una parte en la pesca que se haga en los ratos libre de ocupación (...). Archivo Nacional Histórico de Chile, Fondo Ministerio del Interior, Volumen 197, Informe Nro. 206, f 125, Informe del capitán John Williams al Intendente de Chiloé Domingo Espiñeira, 5 de junio de 1843.

53 Para más información de John Yates, véase: Montiel
A continuación se entregarán antecedentes desconocidos, que contribuyen a dar luces respecto del periodo comprendido entre 1835 y 1841, que van desde cuando William Low deja de prestar servicios a bordo de la Beagle hasta su muerte. Casi por causalidad, en el contexto de una investigación en curso, donde se tuvo acceso ${ }^{55}$, entre otras, al logbook (bitácora) del schooner Betsey, capitán William Noyes, que entre 1836-1838 llevó a cabo una expedición de caza de lobos marinos y nutrias, saliendo desde el puerto norteamericano de New London con destino a la Patagonia. Una vez que arriban a las costas de Chile a inicios de noviembre de 1836, realizan un periplo que abarcó desde la isla San Ambrosio por el norte, tornando al sur hacia los intrincados canales del archipiélago occidental patagónico, finalizando sus actividades cinegéticas en la costa oriental de Patagonia en abril de 1838 .

Desde febrero de 1837 a marzo de 1838, los loberos norteamericanos realizaron una intensivo recorrido cinegético que abarcó desde la isla Huafo ${ }^{56}$ hasta el golfo de Penas. El 5 de octubre de 1837, la bitácora de la goleta Betsey registra que cuando se aprestaban a fondear en la isla de las Cabras (Goat island anota la bitácora), se encuentran con el capitán Low con una pequeña goleta proveniente desde San Carlos ${ }^{57}$. Tres días más tarde, en las cercanías de aquella isla, los loberos yankees encuentran a cinco infortunados náufragos que decían ser sus compatriotas, uno de los cuales toma pasaje a San Carlos en la pequeña goleta del capitán Low. Otro encuentro con el lobero británico se produce el 31 de octubre, presumiblemente en la isla Gran Guayteca. La

(2008).

54 De acuerdo a John Williams (Anrique, 1901, p. 21), la isla de las Cabras corresponde a la isla Inchemó $\left(42^{\circ} 25^{\prime} \mathrm{S}-73^{\circ} 35^{\prime} \mathrm{O}\right)$, las más austral del grupo de los

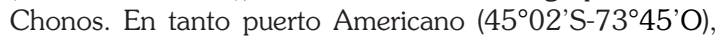
corresponde a una bahía situada en el extremo suroeste de la isla Tangbac, en el canal Moraleda.

55 Revisión documental llevada a cabo en la G. W. Blunt White Library, dependiente del Mystic Seaport Museum, en la localidad de Mystic, Connecticut, financiada por el Programa de Becas de Pasantía Doctoral, Comisión Nacional de investigación Científica y Tecnológica (CONICYT).

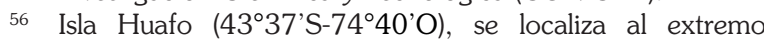
suroeste de la isla de Chiloé.

57 Logbook of the Betsey (Log 6), G. W. Blunt White Library, Mystic Seaport Museum, Inc. 
última mención de Low que contiene la bitácora, refiere que este realiza una visita a la cubierta de la Betsey el 23 de enero de 1838.

Los antecedentes extraídos desde la citada bitácora, en conjunto con la información que en su momento recabó Espiñeira, confirman positivamente que Low efectivamente siguió dedicándose a la misma actividad que por años desarrolló en las Falkland y Patagonia, sólo que a partir de 1835, cazará mamíferos marinos teniendo como base algún lugar de la isla de Chiloé, probablemente Quellón o alguna de las islas cercanas, tales como Cailín, Laitec o Coldita ${ }^{58}$, lugares donde hoy en día la presencia del apellido Low se encuentra plenamente vigente.

En consonancia con lo anterior, el registro de matrimonios de la Parroquia de Castro del mes de julio de 1835 consigna lo siguiente: En veinte y cinco del corriente mes, previas las diligencias de estilo, casé a Don Guillermo Low, soltero, natural de Londres, legitimo de Guillermo y María Pactu, con Rosa Aguilar, soltera, natural de Yutuy, legítima de Victor y Mercedes Barrientos (... $)^{59}$.

El citado registro corresponde al matrimonio de William (Guillermo) Low con una mujer chilota de una pequeña localidad situada en la península de Rilán, frente a la ciudad de Castro, enlace que se llevó a cabo luego de poco más de 5 meses de su radicación en Chiloé, inicialmente en Ancud. Dos años más tarde, el libro de matrimonios de la Parroquia de Queilen ${ }^{60}$ consigna que en 1857 Guillermo Low Aguilar (nacido en 1837 en Quellón), se casa con Rosa Garay Vera (nacida en 1838 en Quellón), información que indicaría que Guillermo Low Aguilar es el primer hijo que se conozca del lobero escocés en tierras chilotas. El mismo registro da cuenta de que Low Aguilar y su esposa, tuvieron cinco hijos y dos hijas, los que en definitiva serán la base de la descendencia del lobero escocés en la isla de Chiloé, apellido que con el paso del tiempo y flujos migratorios de por medio, cruzará los canales patagónicos para extenderse por las ciudades de Punta Arenas y Puerto Natales.

58 Quellón $\left(43^{\circ} 07^{\prime} \mathrm{S}-73^{\circ} 08^{\prime} \mathrm{O}\right)$, se localiza en el extremo sureste

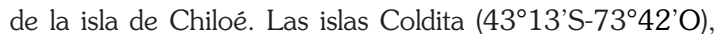

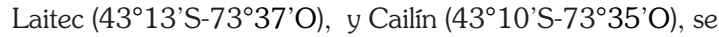
hallan sitas al sur de la ciudad de Quellón.

59 Libro de Matrimonios Parroquia de Castro, Nro. 9, p. 65.
Los antecedentes hasta aquí presentados, permiten realizar algo más que un barrunto respecto del quehacer de William Low a partir de su establecimiento definitivo en Chiloé. Se señalaba en párrafos precedentes que la última expedición que emprendió a bordo de la goleta Unicorn resultó ser un fracaso comercial, al punto que tras este crucero lobero debió desprenderse de aquella goleta, para posteriormente trabajar por un tiempo a bordo de un bote ballenero, y tras zafar de una muerte segura, emplearse como práctico en la expedición hidrográfica en la que participara el celebre naturalista Charles Darwin. Tras esto, por razones que desconocemos, Low decidió radicarse en Chiloé, aún cuando como señalaba Fitz Roy, contaba con la posibilidad de volver a Escocia donde su padre era un respetable agente inmobiliario. Ya en Chiloé, en un principio en la ciudad de Ancud, seguramente con la parte del dinero que le tocó de la venta de la Unicorn, pudo adquirir una embarcación, que de seguro distaba de ser como aquellas con las que por años recorrió las latitudes australes de los océanos Atlántico y Pacífico, ya que como se lee entre líneas en la bitácora del schooner Betsey, el capitán Low poseía una pequeña goleta, comentario realizado en tres de los cuatro encuentros llevados a cabo con aquel, por lo que es dable suponer que aquella embarcación no era más que un cúter o lancha adaptada para la caza de mamíferos marinos. Téngase en cuenta, las dificultades que encontraron quienes debieron organizar la expedición de la goleta Ancud, dado que la referida goleta debió construirse especialmente para tal efecto en un improvisado astillero del puerto homónimo, dada la ausencia de embarcaciones que tuvieran las características para enfrentar tal viaje. En tal sentido, Low debió conformarse con una pequeña goleta como apuntó repetidamente Stephen Perkins, encargado de llevar la bitácora de la goleta norteamericana. Ante tal escenario, William Low decidió establecerse en Chiloé, para seguir dedicándose al oficio que por tanto años desempeñó, claro que en condiciones materiales más precarias de las que habitualmente caracterizaron esta actividad.

Archivo Seminario Pontificio Mayor de Santiago de Chile. 60 Se agradece al arqueólogo, Sr. Christian Díaz Caballero el haber proporcionado el acceso a esta información, habida en Libro de Matrimonios de la Parroquia de Queilen. 


\section{CONCLUSIÓN}

Durante el periodo en que con mayor ímpetu se desarrolló la actividad de caza de lobos marinos en latitudes australes americanas, esto es a fines del siglo XVIII y primera mitad de la centuria siguiente, se produjo una masiva llegada de embarcaciones anglosajonas en busca de los apostaderos de pinnípedos donde otrora estos animales pululaban. Los registros históricos consignan parcialmente el listado de naves que zarparon en pos de las pieles de lobos marinos, quedando excluidos en las fuentes históricas una parte importante de otros cruceros loberos. Algunos logbooks que lograron sobrevivir el paso del tiempo y algunas escasas relaciones de viajes dejadas por capitanes loberos, han permitido conocer pormenores de sus actividades. Sin embargo, la inmensa mayoría de estas expediciones no dejaron registros de bitácora y sólo se conoce de estos, por medio de fuentes indirectas $\mathrm{o}$ alusiones tangenciales en registros oficiales de entradas y salidas de embarcaciones, verbigracia, el Lloyds Register de Londres.

Tal es el caso de la figura del lobero escocés William Low, donde por medio de la revisión y análisis de una serie de fuentes históricas, se ha podido realizar un bosquejo de su trayectoria como cazador de lobos marinos, desde la mirada metodológica de la microhistoria. En función de tal ejercicio inductivo, se procuró develar aspectos desconocidos de esta actividad económica, máxime para el caso de los loberos británicos, donde el número de bitácoras loberas es prácticamente inexistente, al contrario de lo sucedido con los loberos estadounidenses, de quienes se conservan valiosos registros documentales.

La figura de Low, ejemplifica las principales características y circunstancias de quienes se dedicaron a la caza de pinnípedos durante la primera mitad del siglo XIX. Según refiere Jones (1981), quienes se dedicaron a la caza de lobos marinos, estaban en el escalafón inferior de la jerarquía marinera, incluso por debajo de quienes se dedicaron a la caza de ballenas, actividad por lo demás, mucho mas lucrativa. Actividad llevada a cabo fundamentalmente por pequeños propietarios, en medio de un ambiente extremadamente competitivo, dada la cantidad de embarcaciones que se consignan en los registros históricos existentes, sin contar aquellas que no figuran en las fuentes, donde sólo quienes inauguraron la actividad hacia fines del siglo XVIII e inicios del XIX tuvieron la posibilidad de hacer fortuna en una temporada. En los años siguientes los cruceros se hicieron cada vez más largos en recorrido y tiempo, producto de la caza indiscriminada y siempre sujetos a los vaivenes de los precios y, más aún, supeditados a las inclemencias propias de los escenarios geográficos de sus incursiones cinegéticas, de modo tal, que sólo unos pocos tuvieron la fortuna de llegar a acumular algún capital, en tanto que la generalidad de estos intrépidos marineros, difícilmente pudieron recuperar el capital invertido, en medio de los constantes naufragios que les generaban pérdidas totales $\mathrm{y} / \mathrm{o}$ parciales.

Es en este grupo de loberos que engarza Low, quien seguramente pasó sus últimos días modestamente, radicado en algún lugar de el archipiélago chiloense donde decidió echar sus raíces contrayendo matrimonio con una mujer de la zona y, que en circunstancias que desconocemos, falleció en septiembre de 1841, tal vez al igual que su hermano Andrew Low, en el contexto de alguna expedición lobera. Anteriormente, pudo llevar a cabo la actividad mercantil a bordo de diferentes embarcaciones de las que era socio propietario, junto a su hermano, y presumiblemente, con participación del padre. El bergantín (brig) Adeona, los cúter (cutter) Uxbridge y Mercury, la balandra (sloop) Dart y la goleta (schooner) Unicorn formaron parte su inventario de embarcaciones desde 1822 hasta 1833, sin considerar la pequeña goleta con la que continuó su actividad tras radicarse en Chiloé, a partir de 1835.

Por una espacio de aproximadamente 30 años, según se desprende del comentario realizado por Fitz Roy, el lobero escocés William Low no solamente se ocupó de la obtención de pieles para su posterior comercialización, ya que en el transcurso de estos menesteres, fue acumulando una gran acervo de conocimientos respecto del medio geográfico y humano del extremo sur americano, e incluso de lugares tan alejados en el océano Pacífico como las islas Galápagos, que le granjearon a este hombre de mar, una fama que trascendió su propio oficio, dedicándose a práctico de embarcaciones mercantes que buscaban singlar a través del estrecho de Magallanes y de piloto e informante de la expedición hidrográfica británica que se ocupó de relevar las costas sudamericanas 
entre 1826 y 1834.

Particular relevancia tienen las observaciones y comentarios que se desprenden del relato de los hidrógrafos británicos Philip Parker King y Robert Fitz Roy, en relación a los aborígenes canoeros y pedestres de la Patagonia, ya que parte importante de dichos informes se basaron en los testimonios proporcionados por William Low, quien demostró una particular interacción con aborígenes canoeros chono y con los cazadores-recolectores terrestres aónikenk, de quienes pudo conocer de primera fuente testimonios respecto de las costumbres y conocimiento ancestral que de su territorio poseían los habitantes primigenios de Patagonia.

Tal contacto, revela una habitual convivencia pacífica entre el lobero Low y los aborígenes, reflejada en una serie de intercambios materiales y simbólicos, mediados tanto por la natural necesidad de supervivencia de ambas partes, como por una conveniencia recíproca, sin soslayar la existencia de situaciones de conflicto, en particular con los aborígenes canoeros. Este último punto coincide con lo señalado por Martinic (2013), en cuanto a que a los tratos habidos entre foráneos y aborígenes sélknam, kawésqar y yámana "estuvieron signados más por la violencia agresiva que por el trato pacífico" en contraposición al trato abrumadoramente pacífico observado con respecto a los aónikenk (pp. 7 y 13).

\section{AGRADECIMIENTOS}

Se agradece la valiosa información genealógica proporcionada por el arqueólogo radicado en Castro, Sr. Christian Díaz Caballero.

Convenio de Desempeño MAG0901 "Identidad del Fin del Mundo: Patagonia, Tierra del Fuego y Antártica", Ministerio de Educación de Chile.

Programa Beca de Pasantía Doctoral en el Extranjero, CONICYT, Convocatoria 2014.

\section{BIBLIOGRAFÍA}

a) Inéditas

Informe Nro. 82 del Intendente de Chiloé, Domingo Espiñeira, al Ministro de Guerra Manuel Montt, 9 de mayo de 1842.Archivo Nacional Histórico de Chile, Fondo
Ministerio de Marina, Volumen 70.

Informe Nro. 141 del Ministro del Interior, Ramón Luis Yrarrázaval, 30 de septiembre de 1842. Archivo Nacional Histórico de Chile, Fondo Ministerio de Marina, Volumen 71.

Informe Nro. 206, f 125, Informe del capitán John Williams al Intendente de Chiloé Domingo Espiñeira, 5 de junio de 1843.Archivo Nacional Histórico de Chile, Fondo Ministerio del Interior, Volumen 197.

Libro de Matrimonios Parroquia de Castro, Nro. 9, p. 65. Archivo Seminario Pontificio Mayor de Santiago de Chile.

Lloyd's List Marine News 1740 - 1837, Londres: City of London Corporation. Disponible en: https://www. cityoflondon.gov.uk/lloydsList/search.aspx> [2014, Febrero 20].

Lloyds Register, 1 agosto 1823, Gregg International Publisher Limited 1969. Disponible en: http://babel.hathitrust.org/ cgi/pt?id=mdp.39015004293968; view=1up;seq=1

Logbook of the Harriet, (Log107), Manuscript Collection, G. W. Blunt White Library, Mystic Seaport Museum, Inc.

Logbook of the Athenian, (OLog 4), Manuscript Collection, G. W. Blunt White Library, Mystic Seaport Museum, Inc.

Logbook of the Betsey, (OLog 6), Manuscript Collection, G. W. Blunt White Library, Mystic Seaport Museum, Inc. Logbook of the Betsey, (Log 7), Manuscript Collection, G. W. Blunt White Library, Mystic Seaport Museum, Inc.

Registro entrada y salida de embarcaciones, Capitanía de puerto de Valparaíso, planillas 10/09/1826 y 25/09/1826. Archivo Nacional Histórico de Chile, Fondo Ministerio de Marina, Volumen 31, sin foliar.

b) Impresas

Alvarez, R. (2002). Reflexiones en torno a las identidades de las poblaciones canoeras, situadas entre los $44^{\circ}$ y $48^{\circ} \mathrm{de}$ latitud sur, denominadas 'chonos'. Anales del Instituto de la Patagonia, 30, 79-86.

Álvarez, R., Navarro, M., Saavedra, G., \& Donoso, C. (2015). Referencias exploratorias sobre el lago Presidente Ríos, para sortear el Istmo de Ofqui, Península de Taitao, Región de Aysén. Magallania, 43(1), 91-101.

Anrique, N. (1901). Diario de la goleta 'Ancud' al mando del capitán de fragata Don Juan Guillermos, 1843, para tomas posesión del estrecho de Magallanes. Santiago: Imprenta, Litografía y Encuadernación Barcelona.

Barnard, Ch. (1836). Narrative of the sufferings and adventures of capt. Ch. H. Barnard, in a recent voyage round the world, icluding an account of his 
residence for two years on an uninhabited islands. New York, NY: J. P. Callender.

Berguño, J. (1993). Las Shetland del Sur: El ciclo lobero. Primera parte. Boletín Antártico Chileno, 12(1), 5 $-13$.

Braun, A. (1968). Fuerte Bulnes. Buenos Aires: Ediciones Francisco de Aguirre.

Bridges, L. (2000). El último confín de la tierra. Buenos Aires: Editorial Sudamericana.

Busch, B. (1985). The war against The Seals: A history of The North American Seal Fishery. Québec: McGillQueen's University Press.

Cárdenas, R., Grace, C., \& Montiel, D. (1991). Los Chono y los Veliche de Chiloé. Santiago: Ediciones Olimpho.

Caviglia, S. (2012). Malvinas, soberanía, memoria y justicia, 10 de junio de 1829. Rawson: Ministerio de Educación de la Provincia de Chubut.

Coan, Titus (2006). Aventuras en Patagonia, Un viaje de exploración de dos misioneros norteamericanos, noviembre 1833- marzo 1834. (1 $1^{\mathrm{a}}$.ed. español). Buenos Aires: Ed. Zagier \& Urruty.

Cordingly, D. (2008). Cochrane the Dauntless: The Life and Adventures of Thomas Cochrane, 1775-1860. Londres: Bloomsbury Publishing.

Darwin, C. (1839). Narrative of the surveying voyages of His Majesty's Ships Adventure and Beagle between the years 1826 and 1836, describing their examination of the southern shores of South America, and the Beagle's circumnavigation of the globe. Journal and remarks. 1832-1836. London: Henry Colburn.

Darwin, C. (2001). Keynes, R. D. (Ed.). Charles Darwin's Beagle diary. Cambridge: Cambridge University Press.

Dickinson, A. (2007). Seal Fisheries on The Falkland Islands and Dependencies: An historical review. Reserach Maritime History, 34.

Dulles, F. (1930). The old China trade. Boston, MS: Cambridge University Press.

Fanning, E. (1838). Voyages and discoveries in the south seas, 1792-1832. Salem, MS: The Marine Research Society.

Fernández, R., \& Martínez, C. (1991). La pesca de altura en la América española del Setecientos: La fundación de la Real Compañía marítima. En B. Torres (Ed.), Andalucía, América y el mar: Actas de las IX Jornadas de Andalucía y América (pp. 73-91). Sevilla: Junta Consejería de Agricultura y Pesca.

FitzRoy, R. (1839a). Narrative of the surveying voyages of His Majesty's Ships Adventure and Beagle between the years 1826 and 1836, describing their examination of the southern shores of South America, and the
Beagle's circumnavigation of the globe. Proceedings of the second expedition, 1831-36, under the command of Captain Robert Fitz-Roy, R.N. London: Henry Colburn.

FitzRoy, R. (1839b). Narrative of the surveying voyages of His Majesty's Ships Adventure and Beagle between the years 1826 and 1836, describing their examination of the southern shores of South America, and the Beagle's circumnavigation of the globe. Appendix to Volume II. London: Henry Colburn.

Ginzburg, C. (1999). El queso y los gusanos: El cosmos,

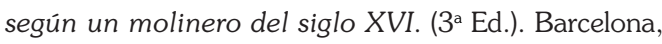
Muchnik Editores.

Greenberg, M. (1951). British rade and the opening of China 1800-42. Brimingham: Cambridge University Press.

Helsby, T. (1968). Rough notes relative to the murders at Port Lewis, Berkley Sound, East Falkland; on the 26th of August 1833. The Falkland Islands Journal, 1968, 21-32.

Iggers, G. (2012). La historiografía del siglo XX: Desde la objetividad científica al desafío posmoderno. Santiago: Fondo de Cultura Económica.

Jones, A. G. E. (1981). The British Southern Whale and Seal Fisheries: Parte I y II. The Great Circle, abril-octubre, 253-275. En A.G.E. Jones. (1986). Ships employed in the South Seas trade: 1775-1861. (Nro. 36). Canberra: Roebuck Society Publication.

Jones, A. G. E. (1986). Ships employed in the South Seas trade : 1775-1861. (Nro. 36). Canberra: Roebuck Society Publication.

Jones, A. G. E. (1991). Ships employed in the South Seas trade : 1775-1859, Volume II (Nro. 46). Melbourne: Roebuck Society Publication.

Jones, A. G. E. (1992). Fur Sealing in The Falkland Islands in The 1820's and 1830's. The Falkland Islands Journal, 1992, 39-48.

Jones, A. G. E. (1993). Earlo voyages to The Falkland islands, 1769-1850. The Falkland Islands Journal, 1993, 1840.

Kirker, J. (1970). Adentures to China. Americans in the Southern Oceans 1792-1812. New York, NY: Oxford University Press.

Legoupil, D., \& Sellier, P. (2004). La sepultura de la Cueva Ayayema (Isla Madre de Dios, archipiélagos occidentales de Patagonia). Magallania, 32,115-124.

Levi, G. (2003). Sobre Microhistoria. En P. Burke. (Ed.), Formas de hacer historia. Madrid: Editorial Alianza.

Lorton, (2012). Falklands Wars: The History of the Falkland Islands: with particular regard to Spanish and 
Argentine pretensions and taking some account of South Georgia, the South Sandwich Islands and Britain's Antarctic Territories. Disponible en: https:// falklandstimeline.files.wordpress.com/2011/07/ falklands-history30.pdf

Martens, C. (1833-1834). Sketchbook III. Cambridge University Press. Disponible en: http://cudl.lib.cam. ac.uk/view/MS-ADD-07983/35

Martinic, M. (1973). Actividad lobera y ballenera en litorales y aguas de Magallanes y Antártica, 1868-1916. Revista de Estudios del Pacífico, 7, 7-26.

Martinic, M. (1987). Navegantes norteamericanos en aguas de Magallanes durante la primera mitad del siglo XIX. Anales del Instituto de la Patagonia, 17, 11-17.

Martinic, M. (1995). Los Aónikenk historia y cultura. Punta Arenas: Ediciones de la Universidad de Magallanes.

Martinic, M. (2006). Historia de la Región Magallánica. Punta Arenas: Ediciones de la Universidad de Magallanes.

Martinic, M. (2007) Convivencia Kaweskar-Aónikenk en el istmo de Brunswick, Patagonia Austral. Un caso de mestizaje cultural. En F. Morello, M. Martinic, A. Prieto \& G. Bahamonde (Eds.). Arqueología de FuegoPatagonia. Levantando piedras, desenterrando huesos... y develando arcanos (pp. 825-837) Punta Arenas: Ediciones CEQUA.

Martinic, M. (2013). Los Aónikenk ¿epitome del buen salvaje?. Magallania, 41(1), 5-27.

Mayorga, M. (2010). Conocimiento geográfico y etnográfico de los cazadores de lobos marinos en aguas australes de Chile. Boletín Antártico Chileno, 29(2), 15-16.

Mill, H. (1905). The siege of the Sout pole. Harvard University Press.

Montiel, D. (2008). Yohn Yates, el Práctico del Sur. Revista Cultura De y Desde Chiloé, 22, 53-73.

Morrell, B. (1832). A narrative of four voyages to the South Sea, North and South Pacific Ocean, Chinese Sea, Ethiopic and Southern Atlanctic Ocean, Indiana $n$
Antarctic Ocean, from the year 1822 to 1831 . New York, NY: J \& J Harper.

Parker King, P. (1839). Narrative of the surveying voyages of His Majesty's Ships Adventure and Beagle between the years 1826 and 1836, describing their examination of the southern shores of South America, and the Beagle's circumnavigation of the globe. Proceedings of the first expedition, 1826-30, under the command of Captain P. Parker King, R.N., F.R.S. London: Henry Colburn.

Pereira, E. (1971). Los primeros contactos entre Chile y los Estados Unidos, 1778-1809. Santiago: Editorial Andrés Bello.

Risopatrón, L. (1924) Diccionario Jeoráfico de Chile. Santiago: Imprenta Universitaria.

Secchi, G. (2007). Diccionario Akal de mitología Universal. (p. 12). Madrid: Ediciones Akal S.A.

Sepúlveda, M. (2011). Pinturas rupestres y tecnología del color en el extremo sur de Chile. Magallania, 39(1), 193210.

Stackpole, E. (1953). The Sea-hunters: The Newengland whalemen during two centuries, 1635-1835. Philadelphia, PA: J. P. Lippincott.

Torrejón, F., Bizama, G., Araneda, A., Aguayom M., Bertrand, S., \& Urrutia, R. (2013). Descifrando la historia ambiental de los archipiélagos de Aysén, Chile: el influjo colonial y la explotación económica-mercantil republicana (siglos XVI-XIX). Magallania, 41(1), 29-52.

Watson, A. (1931). A voyage on the sealer Emeline and the Journal. Zoologica, IX(14), 475-549.

Weddell, J. (1825). Voyage towards the South Pole performed in the years 1822-24, containing an examination of the Antarctic sea, to the seventyfourth degree of latitude, and a visit to Tierra del Fuego, with a particular account of the inhabitants. Londres: Longman, Hurst, Rees, Orme, Brown and Green. 